\title{
La muerte de los miembros de la realeza hispánica medieval a través de los testimonios historiográficos
}

\author{
Death of the Hispanic Royalty's Members Through the \\ Historiographic Testimonies
}

\author{
Margarita CABRERA SÁncheZ \\ Universidad de Córdoba \\ ca1casam@uco.es
}

\section{RESUMEN}

Estudio sobre la muerte de los miembros de la realeza hispánica desde finales del siglo XIII hasta mediados del XVI, utilizando fuentes narrativas relativas a los reyes castellanos y los testimonios historiográficos referidos a la Corona de Aragón, lo que ha permitido obtener nuevos datos, poco conocidos hasta ahora, referidos a las circunstancias en la que se produjo el fallecimiento.

Palabras clave: Realeza. Muerte. Enfermedad. Castilla. Aragón. Siglos XIII-XVI

\begin{abstract}
A study of the deaths of members of the Hispanic royal family from the late thirteenth through the mid-sixteenth centuries, using narrative sources regarding the monarchs of Castile and historiographical testimonies referring to the Crown of Aragon, which have permitted the extraction of previously little-known data regarding the circumstances in which royal deaths occurred.
\end{abstract}

Keywords: Royalty. Death. Illness. Castile. Aragon. 13th-16th centuries

Sumario: 1. La falta de datos referidos a las circunstancias de la muerte. 2. La muerte a consecuencia de la enfermedad. 2.1. Las referencias a enfermedades concretas. 2.2. Las alusiones a enfermedades de naturaleza desconocida. 2.3. La descripcion de la sintomatología. 3. El fallecimiento motivado por otras circunstancias. 3.1. La muerte en el escenario del parto. 3.2. La muerte repentina: accidentes y ataques cardíacos o cerebrales. 3.3. La muerte en la vejez. 3.4. La muerte intencionada: envenenamientos y ejecuciones 
El conocimiento que tenemos sobre el ritual funerario de los miembros de la realeza medieval ${ }^{1}$ contrasta con la escasa información que existe acerca de las enfermedades y de las posibles causas de la muerte de los personajes de sangre real, tal y como puso de manifiesto A. Ruiz-Moreno en un trabajo referido a los reyes castellano-leoneses que fue publicado en los años cuarenta del pasado siglo ${ }^{2}$. Y esa parquedad de datos se debe, como es fácil imaginar, tanto al desconocimiento existente entonces acerca de la naturaleza de las enfermedades y a la identificación de estas últimas con la sintomatología con la que se manifestaban, como a la propia naturaleza de las fuentes consultadas - crónicas y anales sobre todo- para cuyos autores lo verdaderamente importante no era detenerse a analizar el fallecimiento de los monarcas, sino los momentos posteriores al óbito, en los que la proclamación del heredero aseguraba la sucesión dinástica ${ }^{3}$.

Pese a todo, podemos decir que, durante las últimas décadas, la publicación de monografías dedicadas a los miembros de la monarquía hispánica ${ }^{4}$ y de trabajos

${ }^{1}$ Entre los trabajos que se centran en esa cuestión se pueden destacar, en el caso de la monarquía hispánica, los siguientes: Menjot, D.: "Les funérailles des souverains castillans du Bas Moyen Age racontées par les chroniqueurs: une image de la souveranité", Annales de la Faculté des Lettr es et Sciences Humaines de Nice, 39, Niza, (1983), pp. 195-209 y "Un chrétien qui meurt toujours. Les funérailles royales en Castille á la fin du Moyen Age", La idea y el sentimiento de la muerte en la historia y en el arte de la Edad Media, tomo I, Santiago de Compostela, 1987, pp. 127-138; CABrera SÁnchez, M.: "Funerales regios en la Castilla bajomedieval", Acta historica et archaeologica Mediaevalia. Homenatge al Dr. Manuel Ríu, 22, 2, Barcelona, (2001), pp. 537-564. De igual modo, aunque la obra se refiere sobre todo a los siglos posteriores, también se pueden encontrar algunos datos relativos a las ceremonias fúnebres bajomedievales en VARELA, J.: La muerte del rey. El ceremonial funerario de la monarquía española (1500-1885), Madrid, 1990. Sobre los funerales regios en la Francia medieval, ver, entre otros, los trabajos de: Erlande-Brandenburg, A.: Le roi est mort. Etudes sur les funérailles, les sepultures et les tombeaux des юis de France jusqu'à laf n du XIII siècle, París, 1975; Gaude-Ferragu, M.: D'or et de cendres. La mort et les funérailles des princes dans le ryaume de France au bas Moyen Age, Villeneuve-d'Ascq, 2005 y "Les femmes et la mort: sépultures et funérailles des reines et de princesses au bas Moyen Age", en Alduc-Le Bagousse, A.: (dir.) Inhumations de prestige ou prestige de l'inhumation? Expressions du pouvoir dans l'au-delà (IV-XV siècle), Caen, 2009, pp. 383-404.

${ }^{2}$ Ruiz-Moreno, A.: "Enfermedades y muertes de los reyes de Asturias, León y Castilla", Cuadernos de Historia de España, VI, Buenos Aires, (1946), p. 100.

${ }^{3}$ Incluso en aquellos casos en los que se cuenta con documentos en los que se alude específicamente a las circunstancias del fallecimiento de algunos miembros de la realeza, lo habitual es encontrar, únicamente, alusiones a los síntomas. Así lo ha podido comprobar recientemente M. Gaude-Ferragu en el caso de la muerte de la reina Carlota de Saboya, acaecida en 1483. Se da la circunstancia de que, incluso conociéndose los nombres de los médicos que atendieron a la reina, se desconoce la naturaleza de la enfermedad que le costó la vida, ya que, en un documento en el que se relatan sus últimos instantes, sólo se alude a la tos que padeció esta última durante los tres meses anteriores a su muerte (GAUDE-FERRAGU, M.: "L'honneur de la reine: la mort et les funérailles de Charlotte de Savoie (1-14 décembre 1483)", Revue Historique, 652, París, (2009), pp. 782-784).

${ }^{4}$ Entre otros muchos títulos, se pueden citar los dos estudios recientes que M. González ha dedicado a Alfonso X y a Fernando III: González Jiménez, M.: Alfonso X el Sabio, Barcelona, 2004, y Fernando III el Santo, el rey que marcó el destino de España, Sevilla, 2006. 
referidos específicamente a la muerte de los reyes ${ }^{5}$, han permitido completar, en ocasiones, la información que poseíamos sobre las causas del fallecimiento de estos últimos.

En el presente trabajo, hemos querido abordar el tema de la muerte de los miembros de la realeza hispánica desde finales del siglo XIII hasta mediados del siglo XVI y, para ello, además de consultar las fuentes narrativas relativas a los reyes castellanos, hemos utilizado también los testimonios historiográficos referidos a la Corona de Aragón. Por otra parte, se ha recopilado información referente no sólo a los reyes sino también a las reinas ${ }^{6}$, lo que nos ha permitido recabar nuevos datos, poco conocidos hasta ahora, referidos a las circunstancias en las que se produjo su fallecimiento. En cualquier caso, hemos podido comprobar que los relatos cronísticos ofrecen, en ese sentido, una información muy desigual. Así, en algunas ocasiones, sus autores guardan silencio ante las muertes regias hasta el punto de que ni siquiera facilitan la fecha del fallecimiento. Otras veces, lo único que incluyen es una escueta anotación cronológica referida al óbito. Sin embargo, contamos con otros ejemplos en los que, afortunadamente, los autores de esas obras aluden a las circunstancias que rodearon la muerte de los miembros de la realeza, de tal forma que, con más o menos precisión o detalle, podemos conocer las enfermedades que acabaron con la vida de estos últimos, la sintomatología con la que cursaban esas dolencias o incluso si los monarcas terminaron sus días de forma repentina o si se despidieron de este mundo después de haber tenido una larga vida.

\section{LA FALTA DE DATOS REFERIDOS A LAS CIRCUNSTANCIAS DE LA MUERTE}

Como ya se indicó con anterioridad, en algunos casos, las fuentes narrativas no permiten conocer la fecha en la que se produjo el fallecimiento de algunos personajes de sangre real. Se han localizado siete ejemplos en los que faltan esas referencias cronológicas y todos ellos se refieren a reinas. Ello parece poner de manifiesto que los cronistas -en general poco dados a detallar las circunstancias de las muertes regias- eran todavía más escuetos a la hora de aludir al fallecimiento de las reinas. Así, por ejemplo, se desconoce el año en el que murió Violante de Aragón, esposa de Alfonso X. Según señala E. Flórez, la reina falleció en Roncesvalles tras regresar de un viaje que había emprendido en el año $1300^{7}$. Pero se desconoce la fecha exacta de su muerte, pues el autor citado no la consigna, y tampoco aportan ningún dato al

${ }^{5}$ Ver, por ejemplo, los interesantes trabajos de Mitre Fernández, E.: "La muerte del rey: la historiografía hispánica (1200-1348) y la muerte entre las élites”, En la España Medieval , 11, Madrid, (1988), pp. 167-183; "Muerte y memoria del rey en la Castilla bajomedieval”, La idea y el sentimiento de la muerte en la historia y en el arte de la Edad Media, tomo II, Santiago de Compostela, 1992, pp. 17-26 y Una muerte para un rey. Enrique III de Castilla, Valladolid, 2001.

${ }^{6}$ Recientemente, he tenido ocasión de estudiar, además, la mortalidad de los infantes de corta edad utilizando los testimonios cronísticos (CABrera SÁnchez, M.: "La muerte de los niños de sangre real durante el Medievo. Aproximación al tema a través de las crónicas", En la España Medieval, 31, Madrid, (2008), pp. 217-248).

${ }^{7}$ Flórez de Setién, E.: Memorias de las reinas católicas de España, tomo 2, Madrid, 1964, p. 46. 
respecto J. Zurita ${ }^{8}$, R. Muntaner ${ }^{9}$ o la Crónica de Fernando $I V^{10}$. Tampoco se conoce la fecha del fallecimiento de Beatriz de Portugal, segunda esposa de Juan I de Casti1la. La última noticia que se tiene sobre su persona procede de la Crónica de Juan II, según la cual, la reina todavía vivía en el año $1409^{11}$.

La misma parquedad de datos proporcionan los testimonios consultados relativos al fallecimiento de algunas reinas de la corona de Aragón como Violante de Hungría, segunda esposa de Jaime I, y la nuera de esta última, Constanza de Sicilia, esposa de Pedro III el Grande. De la primera de ellas, el cronista J. Zurita se limita a afirmar que, aunque hizo testamento en octubre de 1251, "vivió algunos años después" 12 y con la misma imprecisión cronológica se refiere el cronista citado a la muerte de Constanza de Sicilia, ya que al consignar el fallecimiento en el año 1302 de una de las hijas de la reina, la infanta Violante, se limita a afirmar que "poco antes murió la reina Costanza su madre" 1 . Por su parte, en el relato de R. Muntaner sólo hay una escueta alusión a la muerte de esta última, pero sin aludir a la fecha ${ }^{14}$. Probablemente, muchos años después debió de fallecer Isabel, primera esposa de Jaime II, si se tiene en cuenta que nació en $1283^{15}$ y que, según algunos testimonios, fue muy longeva ${ }^{16}$. $\mathrm{Al}$ parecer, tras enviudar del duque de Bretaña, su segundo esposo, regresó a España, donde murión ${ }^{17}$. También se desconoce el año del fallecimiento de la cuarta esposa de Jaime II, Elisenda de Moncada, y de Margarita de Prades, segunda esposa de Martín el Humano. J. Zurita no hace ninguna alusión a la muerte de la primera y la última mención que recoge el citado autor referida a Margarita de Prades está fechada en el año 1410 , tras la muerte de su esposo ${ }^{18}$.

En otras ocasiones, las fuentes conservadas nos permiten conocer únicamente la fecha en la que se produjo la muerte. Hemos podido comprobar que se da esa circunstancia en una docena de casos, referidos todos ellos a reinas. En 1235 falleció Beatriz de Suabia, primera esposa de Fernando III ${ }^{19}$. No se conocen las causas de su muerte, acaecida, probablemente, a la edad de 37 años $^{20}$. En la Primera crónica general sólo se dice que la reina murió, en el año citado, en la villa de Toro:

${ }^{8}$ Zurita, J.: Anales de la Corona de Aragón, tomo 2, Zaragoza, 1977.

9 Muntaner, R.: Crònica, vol. II, ed. M. Gustà, Barcelona, 1985.

${ }^{10}$ Crónica de Fernando IV, vol. 66, ed. BAE, Madrid, 1953.

${ }^{11}$ Crónica de Juan II, vol. 68, ed. BAE, Madrid, 1953, p. 314. E. Flórez señalaba que no se conocía ni el año ni el lugar en el que murió la reina (Flórez de SETIÉn, E.: Ob. cit., tomo 2, p. 235).

12 Zurita, J.: Anales de la Corona de Aragón, tomo 1, Zaragoza, 1976, p. 565.

13 Zurita, J.: Anales de la Corona de Aragón, tomo 2, ed. cit., p. 624.

14 Muntaner, R.: Crònica, vol. II, ed. cit., p. 48.

15 Flórez de Setién, E.: Ob. cit., tomo 2, p. 62. Sobre su nacimiento ver también la Crónica de Alfonso X, vol. 66, ed. BAE, Madrid, 1953, p. 65. Más recientemente, en 1999, salió a la luz una nueva edición de la citada crónica (ver Crónica de Alfonso X, ed. M. González Jiménez, Murcia, 1999).

16 Según NúÑez de Castro, vivió 100 años (Flórez de Setién, E.: Ob. cit., tomo 2, p. 64).

17 Ibidem. En la Crónica de Juan I no se ha localizado ningún dato referido a su muerte (López de Ayala, P.: Crónica de Juan I, vol. 68, ed. BAE, Madrid, 1953).

18 Zurita, J.: Anales de la Corona de Aragón, tomo 5, Zaragoza, 1980, p. 46.

19 Flórez de Setién, E.: Ob. cit., tomo 1, Madrid, 1964, pp. 572-573.

${ }^{20}$ Al parecer, pudo nacer hacia 1198 (GonzÁlez JimÉnez, M.: Alfonso X el Sabio, Palencia, 1993, p. 12; GonzÁlez Jiménez, M.: Fernando III el Santo..., p. 308, nota 17). J. Delgado llegó a la conclusión de 
[...] Et ese anno [1235] morió la reyna donna Beatriz en la villa de Toro et adoxiéronla al monesterio de las Huelgas de Burgos a enterrar $[\ldots]^{21}$.

Pocos años más tarde, en 1244, falleció Leonor de Castilla, primera esposa de Jaime I aunque, como sucedía en el caso anterior, es esa referencia cronológica lo único que se sabe de la muerte de la citada reina ${ }^{22}$. Y la misma parquedad de datos existe en relación a la muerte de Juana de Ponthieu, la segunda esposa de Fernando III. Según señala E. Flórez, la reina murió en Francia el 16 de marzo de $1278^{23}$.

Casi un siglo después tuvo lugar el fallecimiento de Leonor de Sicilia, tercera esposa de Pedro el Ceremonioso. La crónica de este último sólo consigna que el óbito tuvo lugar en $1375^{24}$. J. Zurita señala que falleció en Barcelona, en el palacio donde residía $^{25}$. Tres años más tarde, en el mes de octubre, falleció Matha de Armagnac, primera esposa de Juan I de Aragón ${ }^{26}$. En la Crónica catalana de Pedro IV, después de aludir al matrimonio de la pareja, sólo se afirma que Matha de Armagnac "visqué poch temps" ${ }^{27}$. Al parecer, murió a los 31 años ${ }^{28}$. En la primavera de 1381 falleció, a los 42 años ${ }^{29}$, Juana Manuel, esposa de Enrique II. Así relata su muerte el cronista P. López de Ayala:

En este año, estando el rey don Juan en la cibdad de Salamanca [...] finó la reyna doña Juana, su madre, miércoles veinte e siete días de marzo deste año. E levaron su cuerpo a enterrar a la cibdad de Toledo $[\ldots]^{30}$.

A finales del año 1406 murieron Sibila de Fortia, cuarta esposa de Pedro el Ceremonioso, y María de Luna, primera esposa de Martín el Humano. Según señala el cronista J. Zurita, Sibila falleció el 24 de noviembre ${ }^{31}$ y María cuando apenas si

que el cadáver momificado de la reina permitía suponer que esta última murió con una edad superior a los 30 años, pero inferior a los 45 (Delgado Roig, J.: "Examen médico legal de unos restos históricos", Archivo Hispalense, IX, n1 27-32, Sevilla, (1948), p. 145).

${ }^{21}$ Primera crónica general de España, vol. II, ed. R. Menéndez Pidal, Madrid, 1977, p. 729.

${ }^{22}$ Flórez de Setién, E.: Ob. cit., tomo 1, p. 569. R. Muntaner no consigna, en su crónica, la fecha del fallecimiento de Leonor de Castilla (MunTANer, R.: Crònica, vol. I. ed. M. Gustà, Barcelona, 1984, p. 28).

${ }^{23}$ Flórez de Setién, E.: Ob. cit., tomo 1, p. 609. En la Crónica de Alfonso X no hay ninguna referencia a su muerte (Crónica de Alfonso $X$, vol. 66, ed. cit).

${ }^{24}$ Chronique catalane de Pierre IV d'Aragon III de Catalogne, ed. A. Pagès, París, 1941, p. 404.

${ }^{25}$ ZuRita, J.: Anales de la Corona de Aragón, tomo 4, Zaragoza, 1973, p. 635.

${ }^{26}$ TAsis i Marca, R.: Pere el Cerimoniós i els seus flls, Barcelona, 1962, p. 151.

${ }^{27}$ Chronique catalane de Pierre IV d'Aragon III de Catalogne, ed. cit., p. 403.

${ }^{28}$ Según señala R. Tasis, tenía 26 años cuando contrajo matrimonio con el rey, en 1373 (TASIS I MARCA, R.: Ob. cit., p. 149).

${ }^{29}$ Había nacido en 1339 (Flórez de Setién, E.: Ob. cit., tomo 2, p. 189).

${ }^{30}$ López de Ayala, P.: Crónica de Juan I, vol. 68, ed. cit., p. 75. El padre Flórez también señala que la reina falleció en 1381 (Flórez de Setién, E.: Ob. cit., tomo 2, p. 200).

31 "Y a 24 del mes de noviembre deste año de 1406 murió la reina doña Sibilia [...]" (ZuRita, J.: Anales de la Corona de Aragón, tomo 4, ed. cit., p. 895). 
había transcurrido un mes, el 29 de diciembre ${ }^{32}$. También es J. Zurita quien consigna la muerte, tres décadas después, de Violante de Aragón, segunda esposa de Juan I de Aragón. El óbito muerte tuvo lugar el 3 de julio de $1431^{33}$, cuando la reina tenía 67 años $^{34}$. Sólo cuatro años después le siguió a la tumba Leonor de Alburquerque, esposa de Fernando de Antequera. Según afirma J. Zurita, murió el 16 de diciembre de 1435 y "fue su muerte muy repentina" "35. La Crónica de Juan II lo refiere así:

[...] fallesció en su monesterio de Medina del Campo a diez y seis días del mes de diciembre del dicho año [...]. E afírmase que esta reyna de Aragón murió muy aceleradamente desque supo la prisión de los reyes de Aragón e de Navarra y del infante don Enrique, sus hijos ${ }^{36}$.

Durante las décadas siguientes, en 1441 y 1458 respectivamente, se produjo la muerte de Blanca de Navarra ${ }^{37}$, primera esposa de Juan II de Aragón, y de María de Aragón, esposa de Alfonso el Magnánimo. Esta última falleció el 4 de septiembre ${ }^{38}$, dos meses antes de cumplir 57 años ${ }^{39}$.

\section{LA MUERTE A CONSECUENCIA DE LA ENFERMEDAD}

Por desgracia, muy pocas veces tenemos la suerte de conocer, buceando en los testimonios historiográficos, la naturaleza de las enfermedades que costaron la vida a los miembros de la realeza. Y ello es así porque, salvo en contadas ocasiones en las que se consignan de manera explícita esas dolencias, lo habitual es que las fuentes consultadas se refieran de una manera general a esas patologías, o en el mejor de los casos, describan únicamente los síntomas con los que cursaban estas últimas.

Pese a todo, hemos podido comprobar que, sobre un total de 44 casos en los que conocemos las circunstancias de la muerte de reyes y reinas, en 25 ocasiones el óbito se produjo como consecuencia de alguna dolencia. En buena parte de los casos, las alusiones a enfermedades prolongadas permiten imaginar que, probablemente, los

32 "Murió la reina doña María, mujer del rey don Martín, a 29 del mes de diciembre [...]" (Ibidem, p. 896).

33 "A 3 de julio deste año murió en la ciudad de Barcelona la reina doña Violante de Aragón [...]" (Zurita, J.: Anales de la Corona de Aragón, tomo 5, ed. cit., p. 775).

${ }^{34}$ Según R. Tasis, tenía 15 años en 1379 cuando contrajo matrimonio con el rey (TASIS I MARCA, R.: Ob. cit., pp. 155-156). Por tanto, debió de nacer en 1364.

${ }^{35}$ Zurita, J.: Anales de la Corona de Aragón, tomo 6, Zaragoza, 1980, p. 108.

${ }^{36}$ Crónica de Juan II, vol. 68, ed. cit., p. 527. P. Carrillo de Huete sólo anota la fecha de la muerte, pero no alude a las causas de la misma (CARrillo de Huete, P.: Crónica del Halconero de Juan II, ed. Carriazo, Granada, 2006, p. 222).

${ }^{37}$ Refiriéndose al año 1441, dice J. Zurita: “[...] falleció estando en Castilla y fue sepultada en el monesterio de Santa María de Nieva [...]" (Zurita, J.: Anales de la Corona de Aragón, tomo 6, ed. cit., p. 270).

38 " [...] falleció la reina doña María de Aragón a 4 del mes de septiembre deste año en el Real de Valencia [...]" (Zurita, J.: Anales de la Corona de Aragón, tomo 7, Zaragoza, 1977, p. 206). E. Flórez también señala que el fallecimiento tuvo lugar en 1458 (Flórez de SetiÉn, E.: Ob. cit., tomo 2, p. 246).

${ }^{39}$ Había nacido en noviembre de 1401 (Flórez de Setién, E.: Ob. cit., tomo 2, p. 243). 
monarcas se despidieron de este mundo en su propio lecho, lo que, de acuerdo con el modelo de muerte ideal que imperaba en el Medievo, les permitió tener un tiempo de preparación para afrontar ese momento decisivo ${ }^{40}$.

\subsection{LAS REFERENCIAS A ENFERMEDADES CONCRETAS}

Afortunadamente, contamos con siete ejemplos en los que se alude, explícitamente, a las dolencias que condujeron a la tumba a los personajes de sangre real.

Entre esas enfermedades destaca, en primer lugar, la tuberculosis. De la información proporcionada por algunos contemporáneos se deduce que Sancho IV fue víctima de ella. Así, por ejemplo, el cronista J. de Loaysa afirma que el rey "fue atacado gravemente por una enfermedad llamada tisis y luchó mucho tiempo contra ella" Por su parte, el famoso literato don Juan Manuel, en el Libro de las armas o de Las tres razones, hace alusión a una visita que hizo al rey, en Madrid, hacia la Navidad de $1294^{42}$, señalando que, estando este último "muy maltrecho en su cama", lo sentó a su lado para conversar con él ${ }^{43}$. Según refiere textualmente el citado escritor, "tomol una tos tan fuerte, non podiendo echar aquello que arrancava de los pechos, que bien otras dos vezes lo tobiemos por muerto"44. Sin embargo, en la Crónica de Sancho IV sólo se alude a la "dolencia grande" que llevó al monarca a ordenar su testamento, en enero de $1295^{45}$. Dos meses más tarde, en el mes de marzo, el estado de debilidad del rey debía de ser tal que, según refiere la crónica, "fízose llevar en andas en cuellos de omes" desde Madrid hasta Toledo ${ }^{46}$, ciudad en la que falleció el 25 de abril ${ }^{47}$, cuando estaba a punto de cumplir 37 años ${ }^{48}$.

Pese a todo, bastantes años antes, los testimonios cronísticos se hacen eco de los problemas graves de salud que afectaron al monarca. Así, por ejemplo, un año antes de la muerte de su padre, es decir, en 1283, el futuro Sancho IV estuvo, al parecer, gravemente enfermo, hasta el punto de que, según la Crónica de Alfonso X, "fue desafuciado de los físicos" ${ }^{\prime 49}$, aunque poco tiempo después se recuperó ${ }^{50}$. Unos años más tarde, concretamente en 1290, según refiere la Crónica de Sancho IV, este último es-

${ }^{40}$ Ver, sobre esta cuestión, ARIÈs, Ph.: El hombre ante la muerte, Madrid, 1983, p. 96.

${ }^{41}$ Loaysa, J. de,: Crónica de los reyes de Castilla, ed. A. García Martínez, Murcia, 1982, p. 159.

${ }^{42}$ Don Juan Manuel, Obras completas, ed. C. Alvar y S. Finci, Madrid, 2007, pp. 992-993.

${ }^{43}$ Ibidem, p. 994.

${ }^{44}$ Ibidem, p. 995.

${ }^{45}$ Dice la crónica: “[...] entendiendo por la su dolencia grande que avía que era de muerte, ordenó su testamento [...]" (Crónica de Sancho IV, vol. 66, ed. BAE, Madrid, 1953, p. 89).

${ }^{46}$ Ibidem.

${ }^{47}$ Ibidem, p. 90.

${ }^{48}$ Había nacido el 12 de mayo de 1258 (Flórez de Setién, E.: Ob. cit., tomo 2, p. 33 ).

${ }^{49}$ Crónica de Alfonso X, vol. 66, ed. BAE, p. 65.

50 “[...] E el infante don Sancho, seyendo en Salamanca, desamparado de los físicos, quiso Dios que terminó en salud [...]" (Ibidem, p. 66). J. Zurita, por su parte, afirma: “[...] llegó el infante a punto de muerte de una grave enfermedad que tuvo estando en Salamanca [...]" (Zurita, J.: Anales de la Corona de Aragón, tomo 2, ed. cit., p. 172). 
tuvo grave a consecuencia de unas fiebres cuartanas ${ }^{51}$, pues, según la crónica, "llegó a punto de muerte e fue desamparado de los físicos por muerto". Pese a todo, terminó por recobrar la salud ${ }^{52}$. Sin embargo, no es posible conocer si esas dolencias fueron, en algunos casos, manifestaciones prematuras de aquella otra que acabó con su vida.

Aunque los testimonios conservados no son tan explícitos como en el caso de Sancho IV, es probable que, más de un siglo después, el rey Enrique III fuese víctima también de la tuberculosis. Es lo que se puede deducir del relato de F. Pérez de Guzmán quien, antes de consignar la muerte del monarca, acaecida el día de Navidad de 1406, y de afirmar que a este último "aquexóle mucho la dolencia" ${ }^{3}$, señalaba:

[...] quando llegó a los diez e siete años ovo muchas y grandes enfermedades, que le enflaquecieron el cuerpo y le dañaron la complesión [...] ca con el trabajo e aflición de la luenga enfermedad hízose mucho triste y enojoso. Era muy grave de ver e de muy áspera conversación, ansí que la mayor parte del tiempo estaba solo e malenconioso $[\ldots]^{54}$.

J. Zurita, por su parte, también se refería a que el monarca "vivió muy doliente" " y A. de Cartagena aludía al hecho de que este último falleció a consecuencia "de la enfermedad que sempre le atormentaba" 56 . Aunque ninguno de los autores citados mencionan a la tuberculosis como posible causa de la muerte de Enrique III, el estado de debilidad física y la delgadez que acompañaron al monarca durante su corta vida -murió cuando acababa de cumplir 27 años-57 permiten pensar que, posiblemente, y tal y como sugirió en su día A. Ruiz-Moreno, el rey fue víctima de esa terrible enfermedad ${ }^{58}$.

En segundo lugar, como cabía de esperar, no faltan ejemplos de personajes de sangre real que perecieron a consecuencia de la que fue, sin duda, la enfermedad más temida del Medievo, es decir, la peste. Así, por ejemplo, nos consta que fue víctima de esa enfermedad el monarca aragonés Alfonso III el Liberal. Según se desprende del relato de J. Zurita, al rey le sorprendió la muerte en medio de los preparativos de su boda con Leonor de Inglaterra ${ }^{99}$. El citado cronista afirma textualmente:

51 "[...] e el rey era y doliente de cuartana que le tomara e salió dende e fuese para Cuenca e afincóle mucho la dolencia [...]" (Crónica de Sancho IV, vol. 66, ed. cit.: p. 83).

${ }^{52}$ Ibidem, p. 84.

${ }^{53}$ Pérez de Guzmán, F.: Generaciones y semblanzas, vol. 68, ed. BAE, Madrid, 1953, p. 700.

${ }^{54}$ Ibidem, p. 699.

${ }_{55}$ Zurita, J.: Anales de la Corona de Aragón, tomo 4, ed. cit., p. 896.

${ }^{56}$ Cartagena, A. de,: Anacephaleosis. Ms. 9436 de la Biblioteca Nacional de Madrid, fol. 178r. Citado por Mitre Fernández, E.: Una muerte para un rey. Enrique III de Castilla, p. 48.

${ }^{57}$ Había nacido el 4 de octubre de 1379 (Flórez de SetiÉn, E.: Ob. cit., tomo 2, p. 220).

${ }^{58}$ Ruiz-Moreno, A.: "Enfermedades y muertes de los reyes de Asturias, León y Castilla", p. 124. P. Barrantes, por su parte, señala que el monarca "fue muerto con yervas que le dio un phisico judío" (Barrantes Maldonado, P.: Ilustraciones de la Casa de Niebla, ed. F. Devís Márquez, Cádiz, 1998, p. 287). Sobre la enfermedad y la muerte del monarca, ver el interesante trabajo de Mitre Fernández, E.: Una muerte para un rey..., pp. 45 y ss.

${ }_{59}$ ZuRita, J.: Anales de la Corona de Aragón, tomo 2, ed. cit., pp. 416-417. 
Aparejábanse por esta causa en Barcelona grandes regocijos y fiestas. Y el rey se comenzó a ejercitar en torneos y justas y juegos de cañas, pero no pasó un mes que en el mayor furor de las fiestas fue salteado de la muerte $[\ldots]^{60}$.

Y continúa diciendo J. Zurita:

Murió este príncipe en tres días en la flor de su juventud, en edad de veintisiete años, de una landre, en Barcelona, a 18 de junio de 1291 años [... $]^{61}$.

Por su parte, R. Muntaner también hace alusión en su crónica a la muerte del rey y señala que a este último le nació una protuberancia en el muslo acompañada de fiebre $^{62}$. La referencia a esa hinchazón o landre que apareció en el cuerpo del monarca permite imaginar que este último murió de peste bubónica.

Muchos años después, en el otoño de 1348, también falleció de peste Leonor de Portugal, segunda esposa de Pedro IV el Ceremonioso. La reina murió, a consecuencia de la Peste Negra, en la localidad castellonense de Jérica. En un capítulo correspondiente al año 1348 y refiriéndose al rey, que se encontraba en Zaragoza, afirma J. Zurita:

[...] salió con la reina -que estaba enferma- camino de Teruel y queriendo detenerse allí para continuar las cortes, fueron heridos de aquella contagión y pestilencia dos caballeros [...]. Y por librar a sí y a la reina del peligro salióse de Teruel y fuese para Ejérica [...]. Pero a la reina se le agravó el mal y murió en aquel lugar en breves días sin dejar hijo ninguno [...]. Esto fue en fin del mes de octubre ${ }^{63}$.

En la Crónica catalana de Pedro IV, aunque no se consigna la fecha del óbito, también se alude a la muerte de la reina a consecuencia de la peste. En la citada crónica se puede leer textualmente lo siguiente:

[...] e la reyna fon agreujada del seu mal en tant que a pochs dies passá d'esta vida en lo dit loch d'Exerica $[\ldots]^{64}$

La citada epidemia debió de ser especialmente mortífera en la ciudad de Zaragoza, pues, según afirma el propio rey en su crónica, "en lo començament del mes d'octubre se moriren en la ciutat tots dies més de .ccc. persones" 65 .

${ }^{60}$ Ibidem, p. 417.

${ }^{61}$ Ibidem. La Crónica de Sancho IV sólo menciona su muerte de forma breve (Crónica de Sancho $I V$, vol. 66, ed. cit., p. 85).

62 “[...] al senyor rey N'Anfòs venc malautia d'una naixença que li féu en la cuixa [...]. E així, meynspreant aquella naixença, mesclà-s'hi febre [...]" (MunTANeR, R.: Crònica, vol. II, ed. cit., p. 33). P. Tomich anotaba textualmente: "[...] lo pres malaltia e de aquella lo rey morí joue [...]" (Томісн, P.: Histories e conquestes dels reys d'Arago e comtes de Catalunya, Valencia, 1970, p. 94).

${ }^{63}$ Zurita, J.: Anales de la Corona de Aragón, tomo 4, ed. cit., p. 159.

${ }^{64}$ Chronique catalane de Pierre IV d'Aragon III de Catalogne, ed. cit., p. 279.

${ }^{65}$ Ibidem, p. 278. 
Durante la primavera del año 1350, como es bien conocido, también murió, a consecuencia de la Peste Negra, el rey Alfonso XI. P. López de Ayala señala que el rey falleció el 27 de marzo ${ }^{66}$ a la edad de 38 años $^{67}$. Según la Crónica de Alfonso XI, estando en el sitio de Gibraltar, el rey "adolesció et ovo una landre"68.

Junto a la tuberculosis y a la peste, también existen alusiones a otro tipo de patologías graves como los tumores. Así, por ejemplo, se cree que el rey Alfonso X pudo fallecer a consecuencia de un proceso cancerígeno. Como es sabido, el monarca murió en Sevilla, en la primavera de $1284^{69}$, a la edad de 62 años ${ }^{70}$. Sin embargo, la crónica del rey aporta pocos datos en relación con las causas de su muerte, pues en ella sólo se afirma:

[...] en este tiempo adolesció el rey don Alfonso en Sevilla en guisa que llegó a muerte $[\ldots]^{71}$.

En su testamento, redactado casi un año y medio antes ${ }^{72}$, el rey se refería a las "grandes enfermedades e en munchas maneras en nuestro cuerpo" ${ }^{\prime 3}$, pero sin especificar nada más. Sin embargo, de la información que facilitan otros testimonios se puede deducir que, probablemente, Alfonso X murió a consecuencia de un tumor facial. Así, por ejemplo, gracias a las Cantigas de Santa María sabemos que el monarca estuvo enfermo muchos antes de su muerte, a causa, tal vez, de las consecuencias de una patada en la cabeza que le propinó un caballo en el año $1269^{74}$. En 1276 se llegó incluso a temer por su vida y, aunque se recuperón ${ }^{75}$, cuatro años más tarde sufrió una recaída ${ }^{76}$. Algunas de esas cantigas, en concreto la número 279, alude al

${ }^{66}$ López de Ayala, P.: Crónica de Pedro I, vol. 66, ed. BAE, Madrid, 1953, p. 404.

${ }^{67}$ Le faltaban varios meses para cumplir 39 años, dado que había nacido el 13 de agosto de 1311 (Flórez de Setién, E.: Ob. cit., tomo 2, p. 110). Sobre el nacimiento del monarca ver también la Crónica de Fernando IV, vol. 66, ed. cit., p. 168.

${ }^{68}$ Crónica de Alfonso XI, vol. 66, ed. BAE, Madrid, 1953, p. 391. J. Zurita señala que el monarca falleció "de una landre de que fue herido habiendo en el real muy grande pestilencia" (ZuritA, J.: Anales de la Corona de Aragón, tomo 4, ed. cit., p. 186).

${ }^{69}$ J. Zurita sólo dice: "falleció el rey en Sevilla en el mes de abril deste año [1284]" (Ibidem, tomo 2, ed. cit., p. 173). J. de Loaysa señala: "[...] sorprendió la muerte al ínclito rey Alfonso en la ciudad de Sevilla [...]" (LoAysa, J.: Crónica de los reyes de Castilla, ed. cit., p. 121).

${ }^{70}$ Había nacido el 23 de noviembre de 1221 (GonzÁlez Jiménez, M.: Alfonso X el Sabio, Palencia, 1993, p. 11).

${ }^{71}$ Crónica de Alfonso X, vol. 66, ed. cit., p. 66.

${ }^{72}$ El testamento está fechado el 8 de noviembre de 1282 (GonZÁlez Jiménez, M.: Alfonso X el Sabio, Barcelona, 2004, p. 358).

${ }^{73}$ Ibidem, p. 361.

${ }^{74}$ KinKade, R. P.: “Alfonso X, cantiga 235 and the events of 1269-1278”, Speculum, 67, (1992), p. 290. Citado por O'Callaghan, J. F.: El rey Sabio. El reinado de Alfonso X de Castilla, Sevilla, 1996, p. 330.

${ }^{75}$ O'Callaghan, J. F.: Ob. cit., pp. 288-289.

${ }^{76}$ Ibidem, p. 304. 
"humor malo" que padecía el rey77. Pero, ¿qué enfermedad fue la que acabó con su vida? Hace ya más de medio siglo, J. Delgado, en su estudio referido al análisis de los restos óseos del monarca y de su madre, Beatriz de Suabia, llegó a la conclusión de que Alfonso X falleció, probablemente, a consecuencia de un tumor localizado en el maxilar superior. El citado autor insistía, además, en el hecho de que ese tumor fue, posiblemente, la causa de la pérdida de visión del ojo izquierdo que el monarca padecía $^{78}$.

Por último, también hay que hacer alusión a otro tipo de dolencias, probablemente menos graves que las anteriormente citadas, pero que, dadas las limitaciones de la época, también llevaron a la tumba a algunos miembros de la realeza. Así, por ejemplo, de los testimonios que han llegado a nosotros se deduce fácilmente que la muerte de Fernando de Antequera se produjo a consecuencia de una afección renal. Según la Crónica de Juan II, el rey de Aragón enfermó gravemente en 1415, es decir, un año antes de su fallecimiento ${ }^{79}$. De la lectura de la citada crónica parece deducirse que el monarca no se llegó a recuperar de esa enfermedad, ya que ese mismo año, tratando de poner fin a las dolencias que le aquejaban y siguiendo el consejo de algunas personas, no dudó en beber agua de beleño, a pesar de que los médicos le advirtieron del peligro que suponía para su salud ingerir la citada sustancia. Así relata la crónica la enfermedad del monarca:

Estando así el rey en Valencia, adolesció de dolor de hijada muy gravemente e un hijo de un ama suya le dixo que él había tenido aquella enfermedad e había sanado con agua de beleño sacado por alquitara, bebida tres veces de tercero en tercero día, e con esto había sanado otros tres o quatro enfermos desta enfermedad. Y el rey quiso saber dellos si era verdad, los quales le respondieron que sí e que convenía que todos los nueve o diez días bebida aquella agua, estuviese en la cama. E como quiera que los físicos le requirieron e amonestaron que no bebiese aquella agua, diciéndole como era cosa muy fuerte, e que aquellos que habían sanado con ella eran hombres robustos e de más fuerte complesión que él, e que por eso que en ninguna manera la debía beber, el rey todavía quiso provar en sí esta experiencia, e bebida el agua no dexó de se levantar y echado un día en su cámara él se amortesió en tal manera que estuvo sin pulsos más de una hora, e por toda la cibdad fue fama que era muerto, e porque creyesen el contrario lo pusieron a una ventana de su palacio porque todos los viesen, e después que

${ }^{77}$ Montoya Martínez, J.: El libro historiado. Signif cado socio-político en los siglos XIII-XIV, Madrid, 2005, p. 187.

${ }^{78}$ Delgado Roig, J.: "Examen médico legal de unos restos históricos", p. 151. Sobre el posible tumor que padeció el rey ver también González Jiménez, M.: Alfonso X el Sabio, Barcelona, 2004, p. 352 , nota 88 .

79 "En este tiempo el rey de Aragón adolesció de tal manera que los físicos le dixeron que si por mar entraba sería en peligro de muerte [...]" (Crónica de Juan II, vol. 68, ed. cit., p. 362). Cuatro años antes, en 1411, también estuvo enfermo durante dos meses, pero finalmente se recuperó. Dice la crónica citada: "[...] adolesçió el infante de ciciones e estuvo doliente bien dos meses. E luego que convalesció, acordaron que el rey e la reina se partiesen para Valladolid [...]" (Ibidem, p. 340). 
esta agua el rey bebió, nunca estuvo bien sano hasta que murió e algunos dicen que le fueron dadas yerbas e otros dicen esto haber seydo la causa de su muerte ${ }^{80}$.

Y en la Crónica incompleta del reinado de Fernando I de Aragón se puede leer lo siguiente:

Y después que el rey bebió d'esta agua nunca anduvo bien sano hasta que murió. Túbose por cierto aver sido esto la causa de su muerte $[\ldots]^{81}$.

La misma idea transmite J. Zurita al hablar de la enfermedad del rey y al afirmar lo siguiente:

[...] fue en tanto aumento que a 7 del mes de agosto le sobrevino un desmayo y le tuvieron por muerto. Y un caballero de su cámara que llamaban Manuel González (que era comendador de Zalamea y Monroy en Aragón) le cerró los ojos teniéndole por muerto. Y por toda la ciudad hubo gran alteración afirmándose que era finado. Y atribuyóse a cierta bebida de una agua de beleño que le dijeron que era gran remedio para el dolor de la ijada y piedra y esto dicen que fue causa de vivir tan poco tiempo después como vivió ${ }^{82}$.

El 13 de septiembre lo visitaron unos embajadores y, según refiere la Crónica de Juan II, "los rescibió en una sala que estaba muy ricamente aderezada y el rey estaba echado en su cama porque estaba muy doliente" "83. A comienzos de noviembre, según relata J. Zurita, estaba "tan agravado de su enfermedad que no podía firmar" último autor señala, aunque sin consignar la fecha, que el monarca decidió viajar a Castilla, pues pensaba que sería beneficioso para él regresar al lugar donde se había criado ${ }^{85}$. Pero su estado de salud fue empeorando. Según refiere la Crónica de Juan II,

[...] se partió de Perpiñán en andas, porque iba muy flaco, e continuó su camino hacia Barcelona, donde le suplicaron le plugiese estar algunos días hasta que fuese más convaleciendo; e con la gran voluntad quel había de venir en Castilla, no se quiso allí detener, e iba caminando dos o tres leguas cada día en sus andas, e iba más enflaqueciendo, e anduvo así hasta un lugar que se dice Igualada, donde le afincó tanto la

\footnotetext{
${ }^{80}$ Ibidem, p. 363.

${ }^{81}$ Crónica incompleta del r einado de Fernando I de Aragón, ed. L. Vela Gormedino, Zaragoza, 1985 , p. 58.

${ }^{82}$ Zurita, J.: Anales de la Corona de Aragón, tomo 5, ed. cit., p. 439. Sobre los problemas de salud del rey consúltese Valla, L., Historia de Fernando de Aragón, ed. S. López Moreda, Madrid, 2002, pp. 196-197.

${ }^{83}$ Crónica de Juan II, vol. 68, ed. cit., p. 364. Ver también, sobre esta cuestión, la Crónica incompleta del reinado de Fernando I de Aragón, ed. cit., p. 61.

${ }^{84}$ Zurita, J.: Anales de la Corona de Aragón, tomo 5, ed. cit., p. 451.

85 Ibidem, p. 467.
} 
enfermedad que hubo de morir, después de haber rescebido con muy gran devoción los sacramentos y hecho su testamento $[\ldots]^{86}$.

Murió el 2 de abril de $1416^{87}$ a los 35 años ${ }^{88}$.

\subsection{LAS ALUSIONES A ENFERMEDADES DE NATURALEZA DESCONOCIDA}

En otras ocasiones, los cronistas, lejos de proporcionar una información tan pormenorizada como la referida a la enfermedad que costó la vida a Fernando de Antequera, se limitan a anotar que la muerte de los monarcas se había producido a consecuencia de una "dolencia" más o menos grave, pero sin añadir ningún dato más al respecto. Se han localizado ocho ejemplos en los que se da esa circunstancia. Así, por ejemplo, al referirse a la muerte de Jaime I, ocurrida en el verano de 1276, J. Zurita dice que al monarca "se le agravó la enfermedad" ${ }^{89}$. De igual modo, el propio rey había hecho alusión, en su crónica, a la gravedad de su estado al señalar:

\section{$[\ldots]$ e fóssem en València a nós cresqué la malaltia $[\ldots]^{90}$.}

Pero no se conocen otros pormenores sobre la muerte del monarca que, en todo caso, tuvo una vida larga, ya que llegar a cumplir los 68 años ${ }^{91}$ debía de ser algo poco habitual dada la corta esperanza de vida de la época. Una prueba de ello es la temprana muerte de Constanza de Portugal, esposa de Fernando IV, cuando sólo tenía 23 años $^{92}$. El fallecimiento se produjo en Sahagún en el año 1313, aunque la Crónica de Alfonso XI se limita a puntualizar que "adolesció y la reina doña Costanza et murió" ${ }^{93}$. Mucha más atención prestan los cronistas al relatar la muerte del rey Fernando IV, acaecida sólo un año antes, pese a lo cual se desconocen también las causas del fallecimiento pues todos los testimonios consultados aluden a una enfermedad que padeció el monarca poco tiempo antes de morir, pero de la que no tenemos información detallada. Al parecer, el rey enfermó gravemente ${ }^{94}$ aproximadamente un mes antes de su fallecimiento. Al menos, es lo que se puede deducir de la lectura de la Crónica de Fernando IV, que, al referirse a la ejecución por orden

${ }^{86}$ Crónica de Juan II, vol. 68, ed. cit., p. 370. J. Zurita dice que el rey "salió de la ciudad en una litera" (ZuRita, J.: Anales de la Corona de Aragón, tomo 5, ed. cit., p. 469).

${ }^{87}$ Crónica de Juan II, vol. 68, ed. cit., p. 370; Zurita, J.: Anales de la Corona de Aragón, tomo 5, ed. cit., p. 470.

${ }^{88}$ Había nacido en noviembre de 1380 (Flórez de Setién, E.: Ob. cit., tomo 2, pp. 220-221).

${ }^{89}$ Zurita, J.: Anales de la Corona de Aragón, tomo 1, ed. cit., p. 770.

${ }^{90}$ Crònica o llibre dels feits, ed. F. Soldevila, Barcelona, 1982, p. 421.

${ }_{91}$ Había nacido a comienzos de febrero de 1208 (Ibidem, p. 5 y pp. 43-44).

${ }_{92}$ Al parecer, nació el 3 de enero de 1290 (Flórez de Setién, E.: Ob. cit., tomo 2, p. 96).

${ }_{93}$ Crónica de Alfonso XI, vol. 66, ed. cit., p. 178. Sobre la reina Constanza, ver el reciente trabajo de: González Mínguez, C.: "Constanza de Portugal, reina de Castilla (1290-1313)", en Val Valdivieso,

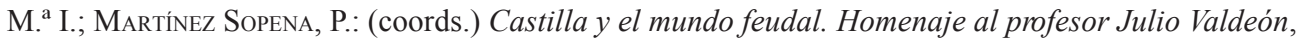
vol. II, Valladolid, 2009, pp. 479-502.

${ }^{94}$ Crónica de Fernando IV, vol. 66, ed. cit., p. 169. 
del rey de los hermanos Carvajal, que tuvo lugar en Martos, señala que dicho suceso ocurrió treinta días antes del fallecimiento del monarca ${ }^{95}$. Del mismo modo, la crónica especifica que, un día después de la muerte de los dos caballeros citados, el rey se dirigió a Alcaudete, lugar donde enfermó de gravedad poco después. En el citado relato cronístico se puede leer, textualmente, lo siguiente:

[...] E ellos muertos otro día fuese el rey para la hueste de Alcaudete [...]. E el rey, estando en esta cerca de Alcaudete, tomóle una dolencia muy grande e afincóle en tal manera que non pudo y estar e vínose para Jahén con la dolencia e non se quiso guardar e comía cada día carne e bebía vino $[\ldots]^{96}$.

Todos los testimonios consultados insisten en el hecho de que el rey fue encontrado muerto en la cama el 7 de septiembre de $1312^{97}$. La crónica del rey señala:

[...] echóse el rey a dormir e un poco después de mediodía falláronle muerto en la cama, en guisa que ningunos le vieron morir $[\ldots]^{98}$

Pero, realmente, no conocemos las causas de la muerte de Fernando IV. F. Simón y Nieto, en su día, apuntaba la posibilidad de que el monarca podía haber padecido tuberculosis ${ }^{99}$, aunque también afirmaba que, tal vez, la muerte del rey tuviera alguna relación con una hinchazón que padeció este último en la pierna derecha unos meses antes de su muerte, hacia el mes de mayo de $1312^{100}$. A esa misma protuberancia alude la crónica del rey, en la que se afirma que "nascióle una nacencia en el anca derecha" ${ }^{101}$. En todo caso, el monarca murió de forma prematura, ya que no había cumplido todavía los 27 años ${ }^{102}$.

Nueve años más tarde, cuando falleció su madre, la reina María de Molina, la lectura de la citada crónica tampoco nos permite conocer la naturaleza de la enfermedad que acabó con la vida de esta última. En ese relato cronístico se puede leer textualmente lo siguiente:

${ }^{95}$ Refiriéndose al día en que tuvo lugar el óbito del monarca, dice la crónica: “[...] E este jueves se cumplieron los treinta días del emplazamiento de los caballeros que mandó matar en Martos [...]" (Ibidem).

${ }^{96}$ Ibidem. Un relato parecido es el que ofrece J. Zurita, quien, refiriéndose a la estancia del monarca en Alcaudete, afirmaba: "[...] estando sobre aquella villa adoleció de una enfermedad tan grave que le fue forzado volver a Jaén [...]" (ZuRITA, J.: Anales de la Corona de Aragón, tomo 2, ed. cit., p. 773).

${ }^{97}$ Crónica de Fernando IV, vol. 66, ed. cit., p. 169.

98 Ibidem. La misma idea transmite J. Zurita al afirmar: "[...] Y habiéndose echado a dormir después de medio día, le hallaron muerto en la cama sin que nadie le viese morir [...]" (Zurita, J.: Anales de la Corona de Aragón, tomo 2, ed. cit., p. 773). El citado cronista señala que Alcaudete se tomó el 4 de septiembre y que "el rey murió dentro de tres días en la vigilia de la fiesta de la Natividad de Nuestra Señora" (Ibidem). D. Barrantes también alude a la muerte del rey mientras dormía la siesta (BARRANTES Maldonado, P.: Ilustraciones de la Casa de Niebla, ed. cit., p. 136).

99 Simón y Nieto, F.: Una página del reinado de Fernando IV, Valladolid, 1912, pp. 65 y 67.

${ }^{100}$ Ibidem, pp. 66 y ss.

${ }^{101}$ Crónica de Fernando IV, vol. 66, ed. cit., p. 168.

102 Nació el 6 de diciembre de 1285 (Flórez de Setién, E.: Ob. cit., tomo 2, p. 65). 
[...] recrecióle a la reyna una grand dolencia, la cual detuvo allí mucho al cardenal et, pensando que mejoraría, fuese el cardenal adelante a Palencia. Pero a la reyna agravósele tanto la enfermedad, que ello entendió bien que era mortal $[\ldots]^{103}$.

Al parecer, según señaló en su día M. Gaibrois, María de Molina estuvo gravemente enferma trece años antes de su fallecimiento, a comienzos del año 1308, hasta el punto de que se temió por su vida. Aunque consiguió hacer frente a esta dolencia $^{104}$, hacia el otoño de ese mismo año volvió a caer enferma, hasta el punto de que solicitó los cuidados de fray Alberto, un médico que residía en Aragón y que, años atrás, ya la había atendido ${ }^{105}$. Sin embargo, se desconoce qué tipo de dolencia padeció la reina y la relación que pudo tener esta última con su muerte, acaecida muchos años después.

De igual modo, se ignoran las causas de la muerte de María de Chipre y de su esposo, el rey Jaime II. Según afirma J. Zurita, la reina había padecido una "muy grave dolencia en fin del mes de marzo de 1319 y vivió después desto pocos días" 106 . Por su parte, el monarca, que sobrevivió a su esposa más de ocho años -murió en noviembre de 1327-, falleció en Barcelona "de una larga indisposición y enfermedad que tuvo, siendo de edad de sesenta y seis años"107.

Ya en la segunda mitad del siglo XIV, los testimonios conservados no facilitan ninguna información referente a la enfermedad que pudo costar la vida a María de Padilla. Lo mismo sucede respecto del monarca Enrique II. De la primera, fallecida en el verano de $1361^{108}$, el cronista P. López de Ayala se limita a señalar que murió "de su dolencia" 109 . En el caso de Enrique de Trastámara, gracias a los datos proporcionados por el cronista citado y por P. Barrantes Maldonado, sabemos que el rey murió a consecuencia de una dolencia que acabó con su vida en pocos días. P. López de Ayala afirma textualmente:

El rey don Enrique, después que el rey de Navarra partió de Sancto Domingo, non se sintió bien, ca ovo una dolencia, e súbito fue muy afincado della [...] e finó a cabo de doce días que se sintiera de la dolencia $[\ldots]^{110}$.

${ }^{103}$ Crónica de Alfonso XI, vol. 66, ed. cit., p. 192. Según la citada crónica, la reina falleció el 1 de junio (Ibidem). P. Barrantes señala que "adolesçió é falleçió en Palençia martes postrero de junio" (Barrantes Maldonado, P.: Ilustraciones de la Casa de Niebla, ed. cit., p. 143).

${ }^{104}$ Gaibrois de Ballesteros, M.: María de Molina tres veces reina, Madrid, 1967, pp. 169-170.

${ }^{105}$ Ibidem, pp. 174-175.

106 Zurita, J.: Anales de la Corona de Aragón, tomo 3, Zaragoza, 1972, p. 142.

${ }^{107}$ Ibidem, p. 282. En la Crónica catalana de Pedro IV también se alude a la muerte de Jaime II, aunque no se aporta ningún dato referido a las causas de la misma. Tan sólo hay una anotación en la que se dice: "[...] En lo segon día de noembre aprés seguent, que es la comemoració dels defunts, lo senyor rey en Jacme, avi nostre, qui era fort veyll, finá sos dies en la ciutat de Barcelona [...]" (Chronique catalane de Pierre IV d'Aragon III de Catalogne, ed. cit., p. 56). El cronista R. Muntaner sólo se alude a una enfermedad que padeció el rey, pero sin añadir más datos (Muntaner, R.: Crònica, vol. II, ed. cit., p. 200).

${ }^{108}$ Flórez de Setién, E.: Ob. cit., tomo 2, p. 173.

${ }^{109}$ López de Ayala, P.: Crónica de Pedro I, vol. 66, ed. cit., p. 513.

${ }^{110}$ López de Ayala, P.: Crónica de Enrique II, vol. 68, ed. BAE, Madrid, 1953, pp. 37-38. 
Por su parte, P. Barrantes señala que se sintió "mal dispuesto de una dolençia que en diez días le quitó la vida" ${ }^{111}$. Pero, en todo caso, se desconoce la naturaleza de esa enfermedad que provocó la muerte del rey en la primavera de $1379^{112}$, cuando tenía 46 años ${ }^{113}$.

\subsection{LA DESCRIPCION DE LA SINTOMATOLOGIA}

Es un hecho habitual que los autores de los relatos cronísticos se limitasen a hacer referencia a los síntomas de las enfermedades que provocaron la muerte de los monarcas, sin plantearse en lo más mínimo el tipo de dolencia que las produjo. Y es que, como es sabido, era frecuente durante el Medievo, y en general hasta la llegada de la época contemporánea, prestar más atención en describir la sintomatología que acompañaba a muchas enfermedades que en consignar la naturaleza de estas últimas, que, en la mayor parte de los casos, no se conocía con exactitud. Y ese hecho se comprueba fácilmente en los tratados médicos medievales ${ }^{114}$, en la documentación de la época ${ }^{115} \mathrm{y}$, por supuesto, en los relatos de los cronistas. En la inmensa mayoría de las ocasiones, la información contenida en las crónicas no resulta demasiado útil para deducir las posibles causas del óbito, pues algunos de los síntomas mencionados en esas obras -es el caso de la fiebre y de la hidropesía- podían estar presentes en patologías de naturaleza muy diversa.

No obstante, contamos con una docena de ejemplos en los que se hace referencia a los síntomas y, especialmente, a los procesos febriles. Así, de la información proporcionada por el cronista R. Muntaner se puede deducir que, probablemente, el rey de Aragón Pedro III el Grande falleció a causa de las complicaciones que se derivaron de un catarro mal curado. Al parecer, cuando el monarca partió de Barcelona, a finales de octubre del año $1285^{116}$, sufrió un enfriamiento que cursó con fiebre, lo cual le obligó a detenerse en la localidad de San Climent. Además, se requirieron incluso los servicios de varios médicos, entre ellos Arnaldo de Vilanova, que viajaron desde Barcelona para asistir al monarca. Afirma textualmente el citado cronista:

E con fo partit de Barcelona [...] se refredà e ab aquell refredament venc-li cremoreta de febre. Així que ell soferí per lo camín en tal guisa que hac a romandre a Sent

${ }^{111}$ Barrantes Maldonado, P.: Ilustraciones de la Casa de Niebla, ed. cit., p. 247.

112 López de Ayala, P.: Crónica de Enrique II, vol. 68, ed. cit., pp. 37-38; Zurita, J.: Anales de la Corona de Aragón, tomo 4, ed. cit., p. 662.

${ }^{113}$ Había nacido en enero de 1333 (Crónica de Alfonso XI, vol. 66, ed. cit., p. 259).

114 Se ha podido constatar esa realidad en el caso de los tratados pediátricos, cuyos capítulos se centran, sobre todo, en analizar los síntomas con los que cursaban las enfermedades infantiles. Sobre este tema, ver mi trabajo titulado: "La transmisión del saber médico: la vida infantil en la Edad Media a través de los tratados pediátricos y de otras fuentes de la época", Meridies, VIII, Córdoba, (2006), pp. 24 y ss.

115 Cabrera Sánchez, M.: La Medicina en Córdoba durante el siglo XV, Córdoba, 2002, p. 20.

116 R. Muntaner no proporciona la fecha en la que el monarca partió de Barcelona, pero J. Zurita señala que fue el 26 de octubre (Zurita, J.: Anales de la Corona de Aragón, tomo 2, ed. cit., p. 255). 
Climent aquell día. E trameteren missatges a Barcelona a maestre Arnau de Vilanova, qui hi era, e d'altres metges $[\ldots]^{117}$.

Pero poco pudieron hacer los médicos por la salud del monarca, que murió poco después, según señala R. Muntaner, el día de San Martín ${ }^{118}$, es decir, el 11 de noviembre. La muerte del rey cuando sólo tenía 46 años ${ }^{119}$ a consecuencia de un enfriamiento y de un proceso febril, que acabaron con su vida en dos semanas, es un claro ejemplo de las limitaciones que tenía la medicina de aquella época para luchar contra las dolencias de tipo infeccioso. De todas formas, es fácil imaginar que ese catarro debió de complicarse hasta afectar muy seriamente al sistema respiratorio.

Otros testimonios cronísticos no son tan explícitos como el de R. Muntaner, aunque coinciden en señalar que el rey enfermó gravemente tras salir de Barcelona. Así relata J. Zurita los últimos días del monarca:

Partió de Barcelona con este propósito a 26 de octubre y, a cuatro leguas del camino de Tarragona, le sobrevino tal enfermedad y dolencia que, sintiéndose muy agraviado della, no pudo pasar adelante y hubo de reparar muy desfallecido en una casería que llamaban el espital de Cervellón. Y allí fué de Barcelona el maestro Arnaldo de Vilanova, que era uno de los más famosos médicos que hubo en sus tiempos. De donde le llevaron en hombros hasta Villafranca de Panadés e iba tal que llegó con grande trabajo y fatiga. La enfermedad le fue arreciando y revenciendo, de tal suerte que se conoció ser muy peligrosa $[\ldots]^{120}$.

B. Desclot, por su parte, afirma que, tras su partida de Barcelona, al rey se le agravó de tal forma la enfermedad que se tuvo que detener en el hospital de Cervelló, a unas cuatro leguas de Barcelona y desde allí fue llevado en un bastidor de madera a la villa de Villafranca de Penedés ${ }^{121}$.

En otras ocasiones, detrás de algunos tipos de fiebre como las tercianas o las cuartanas se escondían enfermedades de tipo infeccioso contra las que poco se podía hacer. Así, por ejemplo, en enero de 1387 falleció, a los 67 años ${ }^{122}$, Pedro IV el Ceremonioso, según afirma R. Tasis i Marca, tras haber padecido fiebres tercianas ${ }^{123}$. J. Zurita sólo alude de forma muy breve a la muerte del rey, señalando que "adoleció y se le agravó de tal manera la enfermedad que luego se entendió que era mortal" 124.

117 Muntaner, R.: Crònica, vol. I, ed. cit., p. 228.

118 Ibidem, p. 231. P. Tomich, refiriéndose a la estancia del rey en Barcelona, señalaba: "[...] aquí lo pres malaltia [...]" (Томісн, P.: Histories e conquestes dels reys d'Arago e comtes de Catalunya, ed. cit., p. 92).

${ }_{119}$ ZuRitA, J.: Anales de la Corona de Aragón, tomo 2, ed. cit., p. 257.

${ }^{120}$ Ibidem, p. 255.

${ }^{121}$ Desclot, B.: Crònica, ed. M. Coll i Alentorn, Barcelona, 1982, p. 365. Según este último cronista, el óbito del monarca tuvo lugar la víspera de San Martín (Ibidem, p. 371).

${ }^{122}$ Había nacido el 5 de septiembre de 1319 (Chronique catalane de Pierr e IV d'Aragon III de Catalogne, ed. cit., p. 52).

${ }^{123}$ TASIS I Marca, R.: Ob. cit., p. 166.

${ }^{124}$ Zurita, J.: Anales de la Corona de Aragón, tomo 4, ed. cit., p. 712. P. Tomich señala: "[...] lo rey dessus dit se en malalti [...]" (Томісн, P.: Histories e conquestes dels $r$ eys d'Arago e comtes de 
Muchas décadas después, en el verano de 1454, se produjo la muerte de Juan II de Castilla ${ }^{125}$. Para explicar las causas del fallecimiento, los cronistas de la época aluden a las fiebres cuartanas que tuvo el monarca. J. Zurita, refiriéndose a esa muerte, señala:

Había adolescido el rey de Castilla estando en Tordesillas de una grave dolencia. Y estuvo cuartanario bien de seis meses y, aunque con diversas medicinas se le quitó la cuartana, tornó a recaer. Y un día se amorteció en el monesterio del Abrojo y fue llevado a Valladolid a donde falleció un lunes a 22 del mes de julio deste año ${ }^{126}$.

Aunque el citado autor no aporta la fecha de la estancia del monarca en la citada localidad de Tordesillas, la Crónica de Juan II señala que la corte se encontraba en la citada villa en diciembre de $1453^{127}$. Según la crónica, a comienzos de 1454 , el monarca estuvo en Avila y posteriormente en Medina, localidad en la que, estando enfermo, permaneció hasta el 6 de junio. Posteriormente, se trasladó a Valladolid, "donde la enfermedad siempre se le fue acrecentando" 128 . Por último, en el relato cronístico se afirma, textualmente, que el monarca murió "de enfermedad de cuartana con otros algunos accidentes que le sobrevinieron"129. Precisamente a esta sintomatología alude también F. Pérez de Guzmán al afirmar lo siguiente:

[...] estando en Valladolid adolesció de quartana doble, que le duró grandes días e, según se dice, regíase muy mal, ca era muy comedor e mal regido. E, como quier que fue libre de la quartana, quedó mal dispuesto de la persona e continuando su mal regimiento, ovo primero algunos acidentes muy fuertes $[\ldots]^{130}$.

El rey murió a los 49 años ${ }^{131}$. Cuatro años más tarde, en el verano de 1458, falleció, a los 64 años ${ }^{132}$, Alfonso V el Magnánimo. Según afirma J. Zurita, a comienzos de mayo, "le tomó frío con fiebre y luego se comenzó a publicar que su mal era peligroso"133. Pero se desconoce cuál fue la dolencia que condujo a la tumba al monarca apenas dos

Catalunya, ed. cit., p. 107).

${ }^{125}$ Según J. Zurita y A. de Palencia, el rey falleció el día 22 de julio (Zurita, J.: Anales de la Corona de Aragón, tomo 7, ed. cit., p. 114; PALEnCIA, A. de,: Crónica de Enrique IV, vol. 257, ed. BAE, Madrid, 1973, p. 54).

126 Zurita, J.: Anales de la Corona de Aragón, tomo 7, ed. cit., p. 114.

${ }^{127}$ En esta localidad nació el infante Alfonso (Crónica de Juan II, vol. 68, ed. cit., p. 684).

128 Ibidem, p. 692.

${ }^{129}$ Ibidem, p. 694.

130 Pérez de Guzmán, F.: Generaciones y semblanzas, vol. 68, ed. cit., p. 714. P. Barrantes, por su parte, afirma, simplemente, que el monarca murió "de su enfermedad" (BArRantes Maldonado, P.: Ilustraciones de la Casa de Niebla, ed. cit., p. 364).

${ }^{131}$ Había nacido el 6 de marzo de 1405 (Flórez de Setién, E.: Ob. cit., tomo 2, p. 246; Crónica de Juan II, vol. 68, ed. cit., p. 695).

132 ZuRITA, J.: Anales de la Corona de Aragón, tomo 7, ed. cit., p. 192.

133 Ibidem, p. 190. 
meses más tarde, el 27 de junio ${ }^{134}$. Diez años después murió una de las cuñadas del monarca, Juana Enríquez, segunda esposa de Juan II de Aragón, aunque los testimonios conservados sólo aluden a la "callentura" que padeció esta última ${ }^{135}$ y a "una tan grave dolencia que le duró muchos días" 136 .

Muchos años después, cuando se produjo la muerte de su nuera, la reina Isabel la Católica, los testimonios que se han conservado se refieren a la fiebre persistente que padeció la reina desde el verano de 1504, es decir, cuatro meses antes de su fallecimiento. En una carta de P. Mártir de Anglería, fechada en el mes de julio de ese año, este último se refería a la "fiebre diaria" de la reina ${ }^{137}$. A comienzos de octubre, el humanista señalaba textualmente en otra carta:

\section{[...] No la abandona la fiebre, ya entrada hasta la médula $[\ldots]^{138}$.}

Además, el citado autor aludía también a la hidropesía que padecía la soberana ${ }^{139}$ síntoma al que también hacía referencia el cronista A. de Santa Cruz, quien relataba, de este modo, la agonía de la reina Católica:

[...] Y desta manera le fue creciendo la calentura, a tanto que muchas veces la sacava de juicio y le hacía decir algunos desatinos. Y como aquel humor se le fuese derramando poco a poco por las venas, vino a caer en hidropesía, de manera que todo su deseo de noche y de día no hera sino beber. Y así se fue hinchando poco a poco y desflaqueciéndosele las fuerças. Y estubo desta manera por espacio de cien días continuos en grande enfermedad $[\ldots]^{140}$.

Aunque la sintomatología descrita no permite deducir la naturaleza de la enfermedad que acabó con la vida de la reina Católica, es posible que esta última fallecie-

${ }^{134}$ Ibidem. El cronista D. Enríquez del Castillo, al referirse a la estancia de Enrique IV en Madrid, se limita a decir que: "[...] llegó la nueva como el rey don Alonso, su tío, era fallescido en la cibdad de Nápoles, de que ovo grand sentimiento [...]" (Enríquez del Castillo, D.: Crónica de Enrique IV, vol. 70, ed. BAE, Madrid, 1953, p. 109).

135 VAlera, D. de,: Memorial de diversas hazañas, vol. 70, ed. BAE, Madrid, 1953, p. 45.

136 Zurita, J.: Anales de la Corona de Aragón, tomo 7, ed. cit., p. 569. El citado cronista señala que la muerte se produjo el 13 de febrero de 1468. P. K. Liss señala que, cuando las cortes se reunieron en Zaragoza, el 6 de febrero de 1468, la reina no pudo presidirlas, pues estaba muy enferma como consecuencia del cáncer de pecho y de cuello que padecía, pero la citada autora no cita las fuentes de las que ha obtenido esta información (Liss, P. K.: Isabel la Católica. Su vida y su tiempo, Madrid, 1998, p. 77). J. Zurita, por su parte, refiriéndose a las cortes celebradas en Zaragoza, sólo alude a la "indispusición de la reina" (Zurita, J.: Anales de la Corona de Aragón, tomo 7, ed. cit., p. 569).

${ }^{137}$ Mártir de Anglería, P.: Epistolario, ed. López de Toro, en Colección de documentos inéditos para la historia de España, vol. X, Madrid, 1955, p. 85.

${ }^{138}$ Ibidem, p. 86.

139 Ibidem, pp. 85-86.

${ }^{140}$ Santa Cruz, A. de,: Crónica de los Reyes Católicos, tomo I, ed. Carriazo, Sevilla, 1951, p. 302. A. Bernáldez, por su parte, no menciona ninguno de estos síntomas, pues sólo afirma que la reina murió "de dolencia e muerte natural" (Bernáldez, A.: Historia de los Reyes Católicos don Fernando y doña Isabel, vol. 70, ed. BAE, Madrid, 1953, p. 722). 
ra a consecuencia de un tumor, si tenemos en cuenta que, en su epístola ya citada de comienzos de octubre, P. Martír de Anglería se refería al "mortífero tumor" que iba "corriéndose entre la piel y la carne"141. La reina Católica, como es bien conocido, murió en Medina del Campo el martes 26 de noviembre de 1504 "entre once y doce del día", según L. Galíndez de Carvajal ${ }^{142}$. Tenía 53 años ${ }^{143}$. Apenas dos años después, cuando murió su yerno, Felipe el Hermoso, los cronistas aludían también a la fiebre que acabó con la vida del joven rey -sólo tenía 28 años-144 en pocos días. Afirma A. de Santa Cruz:

[...] dio al rey don Felipe, nuestro señor, una calentura, de achaque, según algunos, de aver jugado un día mucho a la pelota; del qual travajo se le había recrecido grande sed y avía bebido algo demasiado [...]. De manera que la calentura le fue aumentando poco a poco, en tanta manera que fue causa de dar el ánima a Dios en muy breve tiempo $[\ldots]^{145}$.

P. Mártir de Anglería se limita a decir que:

[...] Inesperadamente, una ligera fiebre se llevó de enmedio al yerno de tan grandes rey y reina. Sucumbió en un abrir y cerrar de ojos $[\ldots]^{146}$.

El cronista L. de Padilla señala:

[...] acabado el juego se sintió mal dispuesto y se bajó a palacio y esa noche tuvo una recia calentura $[\ldots]^{147}$.

Fray Prudencio de Sandoval, por su parte, afirma que el rey se sintió indispuesto una tarde, tras haber hecho ejercicio después de un opulento almuerzo. El citado cronista afirmaba:

[...] El achaque de su muerte fue que don Juan Manuel, su gran privado, alcaide que a la sazón era del castillo, le convidó un día para que se holgase con él. Comió el rey demasiado y jugó a la pelota y hizo otros ejercicios dañosos después de comer, de

141 Mártir de Anglería, P.: Ob. cit., vol. X, p. 86.

142 Galíndez de Carvajal, L.: Anales breves del reinado de los Reyes Católicos don Fernando y doña Isabel, vol. 70, ed. BAE, Madrid, 1953, p. 554. También aporta la misma fecha E. Flórez (FLóREz DE Setién, E.: Ob. cit., tomo 2, p. 384). A. de Santa Cruz, por su parte, señala que el fallecimiento tuvo lugar un día antes, el día 25, "cerca de media noche" (SAnTA Cruz, A. de,: Crónica de los Reyes Católicos, tomo I, ed. cit., 303).

${ }_{143}$ Había nacido el 22 de abril de 1451 (Flórez de Setién, E.: Ob. cit., tomo 2, p. 278).

144 Nació el 22 de junio de 1478 (CAlderón Ortega, J. M.: Felipe el Hermoso, Madrid, 2001, p. 21).

${ }^{145}$ Santa Cruz, A. de,: Crónica de los Reyes Católicos, tomo II, ed. Carriazo, Sevilla, 1951, p. 58.

${ }_{146}$ Mártir de Anglería, P.: Ob. cit., vol. X, pp. 151-152.

147 Padilla, L. de,: Crónica de Felipe I llamado el Hermoso, en Colección de documentos inéditos para la Historia de España, vol. VIII, Madrid, 1846, p. 149. 
manera que aquella mesma tarde, vuelto a palacio, se sintió malo y fuéle apretando la enfermedad de suerte que al séptimo día le arrebató la muerte $[\ldots]^{148}$.

A. Bernáldez apunta la posibilidad de que el monarca fuese víctima de la peste. Dice así:

[...] Duró siete días en la enfermedad, fue curado por sus mismos físicos flamencos visitado y revisto. Fue su mal así como pestilencial e no tubo remedio ni la medicina se lo pudo dar $[\ldots]^{149}$.

Falleció en Burgos el 25 de septiembre de $1506^{150}$.

Pero, como ya se indicó con anterioridad, los testimonios en los que se alude a la muerte de personajes de sangre real también suelen hacer alusión, con mucha frecuencia, a la hidropesía o retención de líquidos en el organismo. Como es fácil imaginar, la mera referencia a un síntoma como ése impide deducir las causas de la muerte, dado que la hidropesía podía acompañar a patologías muy diferentes, entre las que destacan la insuficiencia cardíaca, hepática o renal, ciertos tumores, etc. Además, se da la circunstancia de que, en algunas ocasiones, los cronistas incluso identificaban a la hidropesía con una enfermedad. Así, por ejemplo, al consignar la muerte de Fernando III el Santo, L. de Tuy decía:

[...] era viejo de larga hedad y apesgado con enfermedad de ydropesía, que auía por el trabajo de las batallas que siempre fiziera por el trabajo de los muy malos moros, cansado de gran lasedad, murió desta enfermedad $[\ldots]^{151}$.

Pero, realmente, no se conocen las causas del fallecimiento del monarca ${ }^{152}$ que, como es bien conocido, tuvo lugar en Sevilla, el 30 de mayo de $1252^{153}$, cuando estaba a punto de cumplir 51 años ${ }^{154}$. También se desconoce la enfermedad que causó la muerte de Alfonso IV el Benigno en enero de 1336, cuando tenía $37^{155}$. En la Crónica catalana de Pedro $I V$ se alude a una dolencia que fue la causante de la muerte de su padre. Aunque no se especifica de qué tipo de enfermedad se trataba, sí se alude al hecho de que el rey padecía hidropesía. En la citada crónica se puede leer textualmente lo siguiente:

148 SAndoval, P. de,: Historia de la vida y hechos del emperador Carlos $V$, vol. 80, ed. BAE, Madrid, 1955 , p. 28.

149 Bernáldez, A.: Historia de los Reyes Católicos don Fernando y doña Isabel, vol. 70, ed. cit., p. 726. En uno de los estudios más completos sobre la figura de Felipe el Hermoso, J. M. Calderón se refería a la peste como causante de la muerte del monarca (CALDERÓN ORTEGA, J. M.: Ob. cit., pp. 174-175).

150 Santa Cruz, A. de,: Crónica de los Reyes Católicos, tomo II, ed. cit., p. 58.

151 Tuy, L. de,: Crónica de España, ed. J. Puyol, Madrid, 1926, p. 447.

152 Otros indicios permiten imaginar que el monarca que tal vez padeció un ataque de gota. Ver, al respecto, GonzÁlez Jiménez, M.: Fernando III el Santo..., p. 353-354, nota 57.

${ }_{153}$ Zurita, J.: Anales de la Corona de Aragón, tomo 1, ed. cit., p. 568.

${ }^{154}$ Al parecer, había nacido en el verano de 1201 (González JiméneZ, M.: Fernando III el Santo..., p. 34).

${ }^{155}$ Zurita, J.: Anales de la Corona de Aragón, tomo 3, ed. cit., p. 397. 
[...] per accident de la malaltia, com fos ytropich, agreviá-li la malaltia e finá sos $\operatorname{dies}[\ldots]^{156}$.

Casi dos siglos después, las noticias que han llegado a nosotros aluden también a la hidropesía que padeció Fernando el Católico en el momento de su muerte. Así describía el trance final del rey el cronista A. de Santa Cruz:

[...] Falleció en ábito de Santo Domingo, muy deshecho de las carnes que tenía, por le haber sobrevenido cámaras, que no sólo le quitaron la hinchaçón de la hidropesía pero les deshicieron y dessemejaron de tal manera que no parecía el que solía ser $[\ldots]^{157}$.

Fray Prudencio de Sandoval, por su parte, apuntaba la posibilidad de que el monarca padeciese alguna enfermedad cardíaca. Afirmaba textualmente lo siguiente:

[...] Y a la verdad su enfermedad fue hidropesía con mal de corazón, aunque algunos quisieron decir que le habían dado yerbas, porque se le cayó cierta parte de una quijada; pero no se pudo saber de cierto más de que muchos creyeron que aquel potaje que la reina Germana le dio para hacerle potente, le mostró la virtud natural $[\ldots]^{158}$.

Pero, de hecho, la lectura de esos relatos no permite conocer qué enfermedad acabó con la vida del rey Católico en enero de $1516^{159}$, cuando estaba a punto de cumplir 64 años ${ }^{160}$. En todo caso, gracias a esos testimonios sabemos que el rey enfermó medio año antes de su muerte, es decir, en el verano de 1515. El cronista A. de Santa Cruz señalaba:

[...] una noche, siete de junio, estuvo su alteza tan malo que pensaron que no llegaría a la mañana $[\ldots]^{161}$.

En una carta de P. Mártir de Anglería, fechada el 18 de julio, el citado humanista escribía:

[...] Llevado de un repentino impulso se ha instalado aquí, porque una de las noches próximo pasadas casi se quedó ahogado mientras dormía. Un síncope y el catarro le obstruyeron las fibras del corazón. Uno de los encargados de la vigilancia nocturna

${ }^{156}$ Chronique catalane de Pierne IV d'Aragon III de Catalogne, ed. cit., p. 66. Según una anotación al texto, el término "ytropich" es "hydropich" (Ibidem), es decir, hidrópico.

157 Santa Cruz, A. de,: Crónica de los Reyes Católicos, tomo II, ed. cit., p. 338.

158 Sandoval, P. de,: Historia de la vida y hechos del emperador Carlos V, vol. 80, ed. cit., p. 63.

159 Santa Cruz, A. de,: Crónica de los Reyes Católicos, tomo II, ed. cit., p. 338.

160 Nació el 10 de marzo de 1462 (Liss, P. K.: Ob. cit., p. 76).

${ }^{161}$ Santa Cruz, A. de,: Crónica de los Reyes Católicos, tomo II, ed. cit., p. 302. En parecidos términos, aunque con alguna diferencia en la fecha, se expresa L. Galíndez de Carvajal al decir que: "[...] En una noche a 27 de junio estuvo tan malo que pensaron que no llegara a la mañana [...]" (GALínDEZ de Carvajal, L.: Anales breves del reinado de los Reyes Católicos don Fernando y doña Isabel, vol. 70, ed. cit., p. 561). 
del rey [...] sintió al soberano atragantarse y dar unos horribles ronquidos. Paseaba el centinela por la estancia [...] y acudió al estrépito que formaba el rey, casi a punto de expirar. Entró en el aposento y lo encontró medio muerto, con la cabeza colgando fuera de la cama. Prorrumpió en gritos el desdichado. Acuden los camareros y acomodan al rey en el lecho. Friccionan sus miembros y sacuden todo su cuerpo. Traspuesto, con el habla perdida, torcía los ojos. Le rocían el rostro con agua fría. Por fin volvió en sí $[\ldots]^{162}$.

Un mes más tarde, estando en Segovia, según relata L. Galíndez de Carvajal, el rey "estuvo asaz malo"163. A finales del mes de octubre, los médicos que lo trataban le aconsejaron que abandonase Madrid y se marchase a Sevilla, pues consideraban que el clima cálido de esa ciudad sería beneficioso para su salud ${ }^{164}$. Pero don Fernando no volvió a Sevilla nunca más. Tras permanecer en Plasencia y posteriormente en Trujillo -en esta última ciudad estuvo hasta el día de reyes- ${ }^{165}$ se marchó hacia Madrigalejo, lugar en el que se agravó su enfermedad ${ }^{166}$ y en el que encontró la muerte ${ }^{167}$.

\section{EL FALLECIMIENTO MOTIVADO POR OTRAS CIRCUNSTANCIAS}

\subsection{LA MUERTE EN EL ESCENARIO DEL PARTO}

Como es bien conocido, durante los siglos medievales, el insuficiente desarrollo de las prácticas médicas y las deficientes condiciones higiénicas, así como el desconocimiento de los mecanismos de transmisión de las enfermedades de tipo infeccioso hicieron de la muerte una realidad muy presente en el escenario del parto de la que no se libraron ni las mujeres de sangre real, a pesar de que, como es fácil imaginar, sus mejores condiciones de vida tal vez les permitieron superar, con más probabilidades de éxito, ese difícil trance.

Se han localizado cuatro casos de reinas que fallecieron como consecuencia de un mal parto. Así, por ejemplo, en el otoño de $1310^{168}$ murió, tras dar a luz, Blanca de Anjou, segunda esposa de Jaime II de Aragón. Al menos, es lo que se puede deducir del relato de P. Tomich quien señala textualmente:

${ }^{162}$ Mártir de Anglería, P.: Ob. cit., vol. XI, p. 181.

163 Galíndez de Carvajal, L.: Anales breves del reinado de los Reyes Católicos don Fernando y doña Isabel, vol. 70, ed. cit., p. 561.

164 "Desde Madrid se partió su alteza a la ciudad de Plasençia, para de allí venirse a Sevilla porque los médicos le decían que por ser tierra caliente le sería buena para su mal [...]" (SANTA Cruz, A. de,: Crónica de los Reyes Católicos, tomo II, ed. cit., p. 320).

165 Galíndez de Carvajal, L.: Anales breves del reinado de los Reyes Católicos don Fernando y doña Isabel, vol. 70, ed. cit., p. 561.

166 " [...] Y estando su alteza en este lugar se le agravó en gran manera su enfermedad y le fue dado a entender que estava muy cercano a la muerte [...]" (SANTA Cruz, A. de,: Crónica de los Reyes Católicos, tomo II, ed. cit., p. 331).

${ }^{167}$ Ibidem, p. 338.

168 J. Zurita sólo consigna la fecha de la muerte (Zurita, J.: Anales de la Corona de Aragón, tomo 2, ed. cit., p. 740). 
[...] e amenassen ab si la reyna fa mare e aquí tota la terra li feu gran festa e, apres pocs dies la reyna fa mare, morí $[\ldots]^{169}$.

En el otoño de 1327, durante el alumbramiento de su hijo Sancho, falleció Teresa de Entenza, primera esposa de Alfonso IV el Benigno. Afirma J. Zurita:

“[...] Murió la infanta del parto deste hijo postrero [...]"170.

También contamos con el testimonio de Pedro IV el Ceremonioso, que relata así, en su crónica, la muerte de su madre:

[...] La senyora infanta dona Theresa, mare nostra, finá sos dies en la ciutat de Çaragoça, hon morí de part en lo .xxiiij. día d'octubre de l'any de Nostre Senyor Deu .m.ccc.xxvij., $[\ldots]^{171}$.

Y en otro pasaje de la misma puede leerse lo siguiente:

“[...] E puys nasch un fill qui hac nom Sanxo e per aquest morí nostra mare [...]"172.

Dos décadas más tarde, en la primavera de 1346, falleció, en parecidas circunstancias, María de Navarra, primera esposa de Pedro el Ceremonioso. La reina, que apenas si superaba la veintena ${ }^{173}$, murió pocos días después de haber dado a luz a un niño que sólo vivió un día. Dice el rey en su crónica:

[...] E lo fill mascle que hac fo lo derrer infant, qui morí, que no visch sinó .j. día que fo nat. E la dita reyna morí, aprés pochs dies, d'aquell part, en la ciutat de Valencia, en lo .xvj. día d'abril de l'any de Nostre Senyor Deu m.ccc.xxxxvj. [.... ${ }^{174}$.

Un poco más adelante, el rey vuelve a hacer alusión a la muerte de su esposa, especificando que ésta había tenido un mal parto:

169 Tомісн, P.: Histories e conquestes dels $r$ eys d'Arago e comtes de Catalunya, ed. cit., p. 97. Según J. Hinojosa, murió en el alumbramiento de la infanta Violante (Hinojosa Montalvo, J.: Jaime II y el esplendor de la Corona de Aragón, San Sebastián, 2006, p. 74).

170 Zurita, J.: Anales de la Cor ona de Aragón, tomo 3, ed. cit., p. 281. El citado autor fecha la muerte el 28 de octubre (Ibidem).

${ }^{171}$ Chronique catalane de Pierre IV d'Aragon III de Catalogne, ed. cit., pp. 55-56.

172 Ibidem, p. 14. R. Muntaner también alude a la muerte de Teresa de Entenza, aunque sólo afirma que el óbito tuvo lugar en octubre de 1327 (MunTANER, R.: Crònica, vol. II, ed. cit., p. 199).

${ }^{173}$ Dice J. Zurita que no tenía “doce años cumplidos" cuando se celebró el desposorio con Pedro IV, en enero de 1337 (Zurita, J.: Anales de la Corona de Aragón, tomo 3, ed. cit., p. 430). Por tanto, debió de nacer hacia 1325.

${ }^{174}$ Chronique catalane de Pierre IV d'Aragon III de Catalogne, ed. cit., p. 93. 
[...] E per tal com la reyna nostra muller havía haut mal part e sofferts de grans affanys per lo prenyat [...] la dita nostra muller, así como vera católica e amiga de Deu, reté la sua ánima molt devotament a Deu $[\ldots]^{175}$.

J. Zurita también alude a la muerte de María de Navarra tras dar a luz, aunque fecha el fallecimiento de la reina en 1347. Dice el citado cronista:

[...] Pero la alegría se convirtió presto en llanto porque el infante murió el mismo día después de haberle baptizado, al cual pusieron el nombre del rey su padre. Y de allí a cinco días murió la reina doña María, su madre $[\ldots]^{176}$.

Al parecer, la reina había tenido un embarazo complicado desde el principio. Así, según refiere la Crónica catalana de Pedr o IV, en un viaje que emprendieron los reyes desde Barcelona hasta Valencia, la reina se vió obligada a permanecer en Poblet"177. Poco después, estando el monarca en Valencia, la crónica señala que "la reyna era greument malalta en tant que no li asmava hom vida, majorment per tal com era prenys" ${ }^{178}$. Afortunadamente, su estado de salud mejoró aunque, debido al calor, los reyes permanecieron en Poblet durante todo el verano ${ }^{179}$. J. Zurita también alude a los problemas de salud que padeció María de Navarra durante la gestación, señalando que estuvo "muy enferma y en grande peligro y se dudaba de su vida por estar preñada"180.

También murió en el transcurso del parto, a los 24 años ${ }^{181}$, Leonor de Aragón, primera esposa de Juan I de Castilla. Su fallecimiento tuvo lugar en el verano de $1382^{182}$ en la segoviana villa de Cuéllar, al dar a luz a una hija ${ }^{183}$ que sobrevivió poco tiempo a su madre. Así relata su muerte P. López de Ayala:

Esto así asosegado partió el rey don Juan de Badajoz e vinose para tierra de Toledo e fue algunos días doliente en Madrid. E estando allí sopo nuevas como la reyna doña Leonor, su muger, era finada, e que moriera en la villa de Cuéllar de parto de una hija que encaesció, la cual vivió poco tiempo después $[\ldots]^{184}$.

175 Ibidem, p. 243.

176 ZuRITA, J.: Anales de la Corona de Aragón, tomo 4, ed. cit., p. 30. R. Tasis también se refiere a la muerte, tras el parto, de la reina María de Aragón (TASIS I MARCA, R.: Ob. cit., p. 43).

177 Chronique catalane de Pierre IV d'Aragon III de Catalogne, ed. cit., p. 239.

178 Ibidem, pp. 239-240.

${ }^{179}$ Ibidem, p. 240. Aunque en el texto no se especifica la fecha, es evidente que los reyes debieron de descansar en Poblet desde el mes de agosto en adelante, ya que, si la reina dio a luz en abril, no se pudo quedar embarazada antes del mes de julio.

${ }_{180}$ Zurita, J.: Anales de la Corona de Aragón, tomo 4, ed. cit., p. 20.

${ }^{181}$ En la Crónica catalana de Pedro IV se alude al nacimiento de Leonor de Aragón, que tuvo lugar el 26 de febrero de 1358. Dice así: “[...] nostra molt cara muller, la reyna, parí una filla qui hac nom Alionor, la qual depuys fon reyna de Castella [...]" (Chronique catalane de Pierre IV d'Aragon III de Catalogne, ed. cit., p. 348).

${ }^{182}$ Según E. Flórez, murió el 13 de septiembre (Flórez de Setién, E.: Ob. cit., tomo 2, p. 223).

${ }^{183}$ E. Flórez señala que esta hija se llamó Leonor (Ibidem).

${ }^{184}$ López de Ayala, P.: Crónica de Juan I, vol. 68, ed. cit., p. 78. 
J. Zurita se limita a decir que la reina "murió en Cuéllar de parto"185.

\subsection{LA MUERTE REPENTINA: ACCIDENTES Y ATAQUES CARDIACOS O CEREBRALES}

En ocasiones, la muerte sorprendió de forma repentina e inesperada a algunos miembros de la realeza, bien a consecuencia de un accidente o de un ataque cardíaco o cerebral.

Gracias a P. López de Ayala conocemos con gran detalle las circunstancias en que tuvo lugar el fallecimiento de Juan I, acaecido como consecuencia de las múltiples fracturas que sufrió el monarca tras caerse de un caballo. Así relata el citado cronista el desgraciado accidente que costó la vida al rey:

[...] E acaesció que un domingo, a nueve días del mes de octubre deste año [1390], en la dicha villa de Alcalá de Henares, el rey, después que ovo oído misa, cabalgó en un caballo ruano castellano [...]. E salió fuera de la villa por la puerta que dicen de Burgos e en un barbecho dio el rey de las espuelas al caballo en que iba e, en medio de la carrera, estropezó el caballo e cayó con el rey, en manera que le quebró todo el cuerpo. E los que y estaban fueron a más andar por acorrer al rey e, quando llegaron do estaba, falláronle sin espíritu ninguno, e finado, e quebrados algunos miembros de la caída $[\ldots]^{186}$.

J. Zurita, por su parte, describe así la muerte del monarca:

[...] y arremetiendo el caballo estropezó en la carrera y cayó con el rey y quedó de tal manera atropellado y quebrantado que cuando llegaron a socorrerle ya le hallaron $\sin$ sentido y muerto $[\ldots]^{187}$.

El rey tenía sólo 32 años ${ }^{188}$.

Sólo cinco años más tarde falleció también, de manera repentina, su homónimo Juan I de Aragón en circunstancias no idénticas, pero sí semejantes en cierto modo. Sin embargo, en esta ocasión, parece ser que la muerte del monarca pudo producirse como consecuencia de un paro cardíaco o de un ataque cerebral mientras practicaba la que era una de sus aficiones favoritas: la caza. El rey murió en la primavera de

${ }^{185}$ Zurita, J.: Anales de la Corona de Aragón, tomo 4, ed. cit., p. 684. También se alude a su fallecimiento en la Crónica catalana de Pedro $I V$, aunque no especifican las circunstancias de la muerte (Chronique catalane de Pierre IV d'Aragon III de Catalogne, ed. cit., p. 399).

${ }^{186}$ López de Ayala, P.: Crónica de Juan I, vol. 68, ed. cit., p. 143.

187 Zurita, J.: Anales de la Corona de Aragón, tomo 4, ed. cit., p. 747. P. Barrantes afirma textualmente lo siguiente: "[...] dio de las espuelas al cavallo y, en medio de la carrera, tropezó el cavallo e cayó con el rey, de manera que murió yncontinente [...]" (Barrantes Maldonado, P.: Ilustraciones de la Casa de Niebla, ed. cit., p. 258). Muchos años antes también había muerto, en circunstancias parecidas, Felipe el Hermoso de Francia. En esta ocasión, según relata la crónica de Alfonso XI, al caerse del caballo, el pie del rey se quedó enganchado en el estribo, por lo que el animal lo arrastró (Crónica de Alfonso XI, vol. 66, ed. cit., p. 284).

188 Nació el 24 de agosto de 1358 (Flórez de Setién, E.: Ob. cit., tomo 2, p. 192). 
1395 189, durante una cacería de lobos en el bosque de Foxá. Así relata su muerte P. Tomich:

[...] cassaua dauant lo castell d Orriols en lo bosc de Foxá, corrent una loba, lo dit rey morí $[\ldots]^{190}$.

J. Zurita, utilizando el testimonio de Martín de Alpartil, señala:

[...] andando el rey a caza de lobos un viernes después de haber comido y discurriendo los monteros por sus paradas en un monte, el rey, que iba solo, encontró con una loba muy grande y en viéndola se alteró de suerte que comenzó a temblar y apeándose del caballo en que iba, expiró dentro de una hora $[\ldots]^{191}$.

J. Zurita también recoge el testimonio de otro autor cuyo nombre no menciona, según el cual, el monarca se cayó con el caballo y, cuando fueron a socorrerle, se lo encontraron muerto ${ }^{192}$. Tenía 43 años ${ }^{193}$.

Varias décadas después, y también a los 43 años ${ }^{194}$, falleció de manera repentina, durante la noche, la reina Catalina de Lancáster, esposa de Enrique III de Castilla. Así relata su muerte la Crónica de Juan II

"Miércoles, primero día de junio del año de mil quatrocientos e diez y ocho años, amanesció muerta la reyna doña Catalina $[\ldots]]^{\prime 195}$.

$\mathrm{Su}$ fallecimiento tuvo lugar en Valladolid ${ }^{196} \mathrm{y}$, posiblemente, se produjo a consecuencia de una parada cardíaca, ya que la crónica no alude en ningún momento al hecho de que la reina hubiese estado enferma. Catalina de Lancáster había padecido una especie de parálisis, pues, según señala F. Pérez de Guzmán, "ovo una gran dolencia de perlesía de la qual no quedó bien suelta de la lengua, ni libre del cuerpo"197. Los síntomas aludidos por el citado autor apuntan a una dolencia cerebro vascular y, probablemente, la causa de la muerte fue una repetición de ese problema.

189 ZuRita, J.: Anales de la Corona de Aragón, tomo 4, ed. cit., pp. 791-792.

190 Томісн, P.: Histories e conquestes dels reys d'Arago e comtes de Catalunya, ed. cit., p. 111.

${ }^{191}$ Zurita, J.: Anales de la Corona de Aragón, tomo 4, ed. cit., pp. 791-792.

${ }^{192}$ Ibidem, p. 792. La Crónica de Enrique III no facilita ningún dato al respecto. Por su parte, R. Tasis, quien fecha la muerte del rey en la primavera de 1396, señala que, probablemente, el monarca sufrió algún ataque cerebral o cardíaco (TASIS I MARCA, R.: Ob. cit., p. 194).

${ }^{193}$ Según la Crónica catalana de Pedro IV, había nacido el día de San Juan del año 1351 (Chronique catalane de Pierre IV d'Aragon III de Catalogne, ed. cit., p. 288).

${ }^{194}$ Según E. Flórez, la reina Catalina de Lancáster era cuatro años mayor que su marido (FLóREZ DE Setién, E.: Ob. cit., tomo 2, p. 241). Por tanto, debió de nacer en 1375.

${ }^{195}$ Crónica de Juan II, vol. 68, ed. cit., p. 374. J. Zurita, por su parte, sólo dice que la muerte de la reina tuvo lugar el 1 de junio, sin aportar ningún dato más (Zurita, J.: Anales de la Corona de Aragón, tomo 5, ed. cit., p. 512).

${ }^{196}$ Flórez de Setién, E.: Ob. cit., tomo 2, p. 252. En The Brut or the chronicles of England, ed. F. W. D. Brie, Londres, 2000, no hay ninguna alusión al fallecimiento de la reina Catalina de Lancáster.

197 Pérez de Guzmán, F.: Generaciones y semblanzas, vol. 68, ed. cit., p. 700. 


\subsection{LA MUERTE EN LA VEJEZ}

Junto a estos testimonios de muertes acaecidas de manera inesperada e incluso prematura, no faltan ejemplos de personajes de sangre real que fueron especialmente longevos y cuyo fallecimiento, según los datos que han llegado a nosotros, se produjo a causa del deterioro físico propio de la vejez. Como es obvio, en último término, la muerte se produciría debido a determinadas dolencias que resultarían especialmente letales en la última etapa de la vida o como resultado de una parada cardíaca o respiratoria, aunque las fuentes consultadas sólo se limitan a puntualizar que el fallecimiento se había producido a consecuencia de la vejez. Sucede así en el caso de Juan II de Aragón, quien, entre todos los ejemplos que hemos conseguido recopilar, fue el monarca más longevo, ya que vivió hasta los 82 años ${ }^{198}$. Al parecer, según señala J. Zurita, unos antes de su muerte, en el año 1473, el rey "adoleció de grave enfermedad". En opinión de J. Zurita, la vida del monarca corrió peligro como consecuencia de los "excesivos trabajos" que había padecido durante el cerco de Perpiñán "en tanta vejez"199. Tres años más tarde, el cronista alude al "mal de un pie" que padeció el rey ${ }^{200}$. J. Zurita señala que su muerte tuvo lugar en 1479, "un martes a 19 de enero a la siete horas antes de mediodía" y afirma que el monarca había estado varios días enfermo en el palacio del obispo de Barcelona, "más de vejez que de dolencia" 201 .

Casi dos décadas más tarde se produjo la muerte de Isabel de Portugal, segunda esposa de Juan II de Castilla. Aunque esta última no fue tan longeva como Juan II de Aragón - la reina falleció en el verano de 1496 cuando rondaba los setenta años ${ }^{202}$ los testimonios que han llegado hasta nosotros coinciden en señalar que murió de vieja. Así, P. Mártir afirmaba que su muerte había sido natural porque estaba "consumida y extenuada por la vejez" "203. A. de Santa Cruz, por su parte, declaraba lo mismo en su crónica, al afirmar que, "aunque murió bien vieja, fue bien llorada"

Muchos años después, los testimonios conservados permiten imaginar que, tal vez, fue también el desgaste propio de la senectud el causante de la muerte de Juana la Loca. Según afirma L. Pfandl, a la enfermedad mental que padeció esta última hubo que añadir una parálisis parcial de una pierna que, al parecer, empezó a padecer

${ }_{198}$ ZuRita, J.: Anales de la Corona de Aragón, tomo 8, Zaragoza, p. 355.

${ }^{199}$ Ibidem, tomo 7, ed. cit., p. 719.

${ }^{200}$ Ibidem, tomo 8, ed. cit., p. 210.

${ }^{201}$ Ibidem, p. 355. Para H. del Pulgar la muerte del rey se produjo el 20 de enero (Pulgar, H. del.: Crónica de los Reyes Católicos, ed. BAE, vol. 70, Madrid, 1953, p. 342). L. Galíndez de Carvajal afirma que el fallecimiento tuvo lugar el día 19 (GALíndeZ DE CARVAJAL, L.: Anales breves del reinado de los Reyes Católicos don Fernando y doña Isabel, vol. 70, ed. cit., p. 542).

${ }^{202} \mathrm{Al}$ parecer, apenas tenía 27 años cuando murió su marido (Liss, P. K.: Ob. cit., p. 17). Por tanto, debió de nacer hacia 1427. Según E. Flórez, la reina murió el 15 de agosto (Flórez de Setién, E.: Ob. cit., tomo 2, p. 281).

${ }^{203}$ Mártir de Anglería, P.: Ob. cit., vol. IX, p. 325.

${ }^{204}$ Santa Cruz, A. de,: Crónica de los Reyes Católicos, tomo I, ed. cit., p. 156. L. Galíndez de Carvajal, en el capítulo correspondiente al año 1496, sólo señala: "[...] Y fallesció la reina doña Isabel, que estaba en Arévalo [...]" (Galíndez de Carvajal, L.: Anales breves del reinado de los Reyes Católicos don Fernando y doña Isabel, vol. 70, ed. cit., p. 549). 
la reina a partir del año 1551 . Esa falta de movilidad, unida a la falta de aseo -parece ser que la reina no permitía que la aseasen- trajo como consecuencia un importante deterioro físico de doña Juana, cuyo cuerpo se cubrió de heridas y llagas ${ }^{205}$. Fray Prudencio de Sandoval afirmaba lo siguiente:

[...] enfermó gravísimamente en el principio de este año [1555] y fue tan grande el trabajo que se tuvo con ella para que se dejase curar y quisiese comer, que he visto cartas que el marqués de Denia escribió a la princesa y a otros, en que se lastimaba mucho del gran mal que la reina tenía y cuan impaciente y furiosa estaba y que de día y de noche no hacía otra cosa sino dar voces, con que a todos sus criados traía fatigados y con pena y el bueno del marqués, que lo sentía grandemente. Duróle este mal desde enero hasta once de abril $[\ldots]^{206}$.

Precisamente en una de las cartas que el marqués de Denia dirigió a Carlos V, fechada el 17 de marzo de 1555, el citado marqués escribía:

[...] aunque a Dios gracias en las llagas hay mejoría, en lo demás pareçe que se va agrauiando el mal [...] por lo poco que come y duerme y reposa. Y por la flaqueza que muestra, no puede dexar de pasar su mal mucho trabajo y yo sentirle mayor a caussa de no querer reçiuir ningún benefiçio que le pueda aprouechar $[\ldots]^{207}$.

Pero su estado de salud debió de ir empeorando, dado que la reina murió en la madrugada del 12 de abril de ese año ${ }^{208}$. Tenía 75 años $^{209}$.

\subsection{LA MUERTE INTENCIONADA: ENVENENAMIENTOS Y EJECUCIONES}

Contamos con cinco ejemplos de personajes de sangre real que, al parecer, pudieron ser envenenados. El primero es el de María de Portugal, esposa de Alfonso XI, que falleció en Evora, el 18 de enero de $1357^{210}$. De la lectura de la Crónica de Pedro I se deduce que la reina fue envenenada por su padre. En la citada crónica se puede leer textualmente lo siguiente:

“[...] llegaron nuevas al rey don Pedro como la reyna doña María, su madre, era finada, e que moriera en el regno de Portogal [...]".

${ }^{205}$ Pfandl, L.: Juana la Loca. Madre del emperador Carlos V. Su vida. Su tiempo. Su culpa, Madrid, 1999, p. 100.

206 Sandoval, P. de,: Historia de la vida y hechos del emperador Carlos V, vol. 82, ed. cit., p. 440.

207 Fernández Alvarez, M.: Corpus documental de Carlos V, IV, Salamanca, 1979, p. 197. En esa misma carta, el marqués de Denia aludía a los cuidados que se proporcionaban a doña Juana para tratar de aliviar sus molestias, entre los cuales destacaba el empleo de unos colchones de lienzo que sustituyeron a unas almohadas de paño en las que reposaba la reina con anterioridad (Ibidem).

${ }^{208}$ Ibidem, p. 206.

${ }^{209}$ Había nacido en Toledo el 6 de noviembre de 1479 (Flórez De SetiÉN, E.: Ob. cit., tomo 2, p. 390).

${ }^{210}$ Ibidem, p. 144. 
Más adelante, el cronista añade:

[...] segund fue la fama, dixeron que el rey don Alfonso de Portogal, su padre della, le ficiera dar hierbas con que moriese, por quanto non se pagaba de la fama que oía della $^{211}$.

La reina murió a los 44 años ${ }^{212}$. Casi un siglo después también pereció, víctima de un envenenamiento, María de Aragón, primera esposa de Juan II. La reina, que debía de rondar los 43 años $^{213}$, falleció a comienzos del año 1445 . No conocemos la fecha exacta de su muerte, aunque todos los datos que poseemos señalan que esta última se produjo poco tiempo después del fallecimiento de su hermana doña Leonor, reina de Portugal, que tuvo lugar el 18 de febrero del año citado ${ }^{214}$. Al parecer, según ha quedado constancia en la Crónica de Juan II, el monarca se encontraba en la localidad segoviana de El Espinar cuando murió su esposa. Dice así:

[...] vínole nueva como la reyna doña María, su muger, que estaba en Villacastín, aldea de Segovia, era fallescida $[\ldots]^{215}$.

Todos los testimonios que han llegado a nosotros inciden en el hecho de que, con toda probabilidad, tanto María de Aragón como su hermana fueron envenenadas. Al menos, así lo podemos deducir al leer la crónica del rey, en la que se dice lo siguiente:

[...] no estuvo enferma más de quatro días e ningún otro sentimiento hubo salvo dolor de cabeza e saliéronle por todo el cuerpo e por los brazos e manos e rostro manchas cárdenas hinchadas como si oviera recibido azotes y estas mesmas ronchas salieron a la reyna de Portogal. E por esto se cree estas dos señoras reynas ser muertas de yerbas como dicho es $[\ldots]^{216}$.

La misma idea sugiere J. Zurita, quien afirma textualmente:

[...] Y tuvieron por cierto las gentes que les fueron dadas yerbas; y dello hubo muchas señales y fue inculpado el condestable don Alvaro de Luna, que con su sabiduría y consejo se aparejó el veneno con que murieron las reinas y que fue manifiestamente

${ }^{211}$ López de Ayala, P.: Crónica de Pedro I, vol. 66, ed. cit., p. 477. En la crónica de F. Lopes no se alude a las circunstancias de la muerte de la reina (Lopes, F.: Chronique du roi D. Pedro I, ed. G. Macchi, París, 1985, pp. 24 y ss).

${ }^{212}$ Nació en 1313 (Flórez de SetiÉn, E.: Ob. cit., tomo 2, p. 126).

${ }^{213}$ Debió de nacer en 1402 si se tiene en cuenta que, según A. García de Santa María, tenía 7 años en abril de 1409 (García de Santa María, A.: Crónica de Juan II de Castilla, ed. Carriazo, Madrid, 1982, p. 287).

${ }^{214}$ Flórez de Setién, E.: Ob. cit., tomo 2, p. 271; Zurita, J.: Anales de la Corona de Aragón, tomo 6, ed. cit., p. 333.

${ }^{215}$ Crónica de Juan II, vol. 68, ed. cit., p. 625.

216 Ibidem. 
entendido por la repentina muerte de la reina de Portugal y por la celeridad del veneno con que murió, y que todos los indicios y señales del se vieron en su cuerpo siendo defunta, y que con el mismo fue muerta la reina de Castilla, su hermana $[\ldots]^{217}$.

En diciembre de 1464, según E. Flórez, la reina Blanca de Navarra, primera esposa de Enrique IV, murió envenenada por una dama de la condesa de Foix ${ }^{218}$. Tenía 39 años ${ }^{219}$.

Una década más tarde, el propio monarca Enrique IV parece ser que fue también víctima de un envenenamiento. Al parecer, según algunos cronistas de la época, el rey estaba aquejado de algún tipo de enfermedad renal. D. Enríquez del Castillo afirma que el rey "padecía mal de la ijada" 220 . y H. del Pulgar señala que "era doliente de la hijada e de piedra y esta dolencia le fatigaba mucho a menudo" 221.

Sin embargo, tal y como ya señaló en su día G. Marañón, en su clásico estudio sobre el monarca, todo conduce a pensar que este último murió como consecuencia de un envenenamiento. Al menos, es lo que se deduce de los transtornos gastrointestinales que padeció antes de morir, que, a juicio del citado autor, permiten sospechar que fue envenenado ${ }^{222}$. El cronista D. Enríquez del Castillo, al mencionar la estancia del monarca en Madrid, en el otoño de 1474, afirma lo siguiente:

[...] cargó en él tan apoderadamente el mal de sus cámaras e gómito, que luego paresció ser mortal sin remedio alguno, en tanto grado que luego los físicos pronosticaron ser muy cercano su fin. Pero todavía acordaron de lo purgar un domingo por la mañana e purgó livianamente, con que paresció en alguna manera sentirse más aliviado hasta que ovo comido e dormió por espacio de una hora y media muy sosegadamente. E luego que despertó dióle un tan grand dolor de costado y tan agudo que ningún reposo ni sosiego le dexaba tener, en tanto grado que siempre le fue cresciendo e nunca menguando e duróle aquel dolor por espacio de diez horas $[\ldots]^{223}$.

A. de Palencia alude a la fuerte hemorragia que sufrió el rey pocos días antes de su muerte. Dice así:

217 Zurita, J.: Anales de la Corona de Aragón, tomo 6, ed. cit., p. 333. También se refiere al envenenamiento A. de Palencia (Palencia, A. de,: Crónica de Enrique IV, vol. 257, ed. cit., p. 29). P. Carrillo de Huete no hace alusión a la muerte de María de Aragón.

${ }^{218}$ Flórez de Setién, E.: Ob. cit., tomo 2, p. 290. J. Zurita también se refiere al óbito de Blanca de Navarra, aunque no aporta ningún dato más (Zurita, J.: Anales de la Corna de Aragón, tomo 7, ed. cit., p. 489). Los cronistas D. Enríquez del Castillo y A. de Palencia no hacen alusión a su muerte.

${ }^{219}$ Según E. Flórez, tenía 12 años cuando contrajo matrimonio con el rey en el año 1437 (FLórez DE Setién, E.: Ob. cit., tomo 2, p. 283). Por tanto, debió de nacer en 1425.

${ }^{220}$ Enríquez del Castillo, D.: Crónica de Enrique IV, vol. 70, ed. cit., p. 101.

${ }^{221}$ Pulgar, H. del.: Crónica de los Reyes Católicos, vol. 70, ed. cit., p. 251.

222 Marañón, G.: Ensayo biológico sobr e Enrique IV de Castilla y su tiempo , Madrid, 1960, pp. 72-73.

${ }^{223}$ Enríquez del Castillo, D.: Crónica de Enrique IV, vol. 70, ed. cit., p. 221. 
[...] en este último ataque nada aprovechó el repentino y abundante flujo sanguíneo, antes en el espacio de dos días le hizo perder todas sus fuerzas y desde el primero la extremada debilidad le volvió deforme $[\ldots]^{224}$.

D. de Valera, por su parte, también hace alusión al "súpito flugio de sangre" que padeció el monarca ${ }^{225}$. J. Zurita, por su parte, refiere así el óbito del monarca:

[...] fue su muerte de muy recio dolor de costado, aunque andaba ya muy doliente, y los suyos tenían por cierto que murió de veneno que se le dio en Segovia en las fiestas $\mathrm{y}$ vistas que tuvo con su hermana en aquella ciudad ${ }^{226}$.

P. Barrantes también menciona el "dolor de costado" 227 . Por último, en la Crónica incompleta de los Reyes Católicos se alude a la "enfermedad peligrosa" que padeció el monarca ${ }^{228}$. El autor de esta crónica relata, de este modo, la agonía del rey:

[...] y él, así adoleçido, anduuo ansí quinze días doliente y cayendo en cama y leuantándose. Y el postrimero día de su vida leuantose sin pensamiento que de aquel mal ouiese de morir y fuese a un monesterio que él auía hecho cabe Madrid, que llamauan Santa María del Paso Real, que agora se dize San Jerónimo el Real, y después a la tarde, tornado a sus palaçios a la villa de Madrid, aquexole más la enfermedad y a la media noche imbió por el prior del monesterio y quando el prior uino serían las dos horas después de media noche y, ya quando él llegó, el rey estaua tan aquexado de la muerte que muy poco espaçio tuuo en entender en las cosas de su ánima [...]. Y como fue muy aquexado de los suyos, demandó que quánto tenía de vida: dixiéronle que non tenía una hora. El fue desto tanto turbado y del temor de la muerte, socorriose al uno de los prinçipales físicos que allí estauan si podría veuir un día y ellos le dixieron que non podría veuir media hora y el rey, con grand anxia de veuir, le dixo: ¿non podría bastar vuestro saber a me hazer veuir dos horas? y el físico le dixo que non podía hazerle veuir una, segund ya la virtud tenía perdida y la enfermedad esforçada. Y el rey, oyendo el corto plazo de su vida, sin poder entender en su testamento, los pensamientos de la muerte le hezieron oluidar los cuydados deste mundo y así, ante de media hora después que aquello le dixo el físico, espiró $[\ldots]^{229}$.

El monarca murió la madrugada del 11 de diciembre de $1474^{230}$, cundo estaba a punto de cumplir 50 años ${ }^{231}$.

${ }^{224}$ Palencia, A. de,: Crónica de Enrique IV, vol. 258, ed. BAE, Madrid, 1975, p. 153.

225 VAlera, D. de,: Memorial de diversas hazañas, vol. 70, ed. cit., p. 94.

226 Zurita, J.: Anales de la Corona de Aragón, tomo 8, ed. cit., p. 1977, p. 63.

227 Barrantes Maldonado, P.: Ilustraciones de la Casa de Niebla, ed. cit., p. 420.

${ }_{228}$ Crónica incompleta de los Reyes Católicos (1469-1476). Según un manuscrito anónimo de la época, Madrid, 1934, p. 128.

${ }^{229}$ Ibidem, pp. 128-129.

${ }^{230}$ Enríquez del Castillo, D.: Crónica de Enrique IV, vol. 70, ed. cit., p. 221.

${ }^{231}$ Había nacido el 5 de enero de 1425 (Flórez de Setién, E.: Ob. cit., tomo 2, p. 265). Sobre su nacimiento ver también la Crónica de Juan II, vol. 68, ed. cit., p. 429. 
Medio año más tarde le siguió a la tumba su segunda esposa, Juana de Portugal ${ }^{232}$. No se conoce con certeza la causa de su muerte a los 36 años $^{233}$, ya que, aunque la mayor parte de los testimonios conservados aluden al hecho de que la reina fue envenenada, también señalan que esta última pudo fallecer a consecuencia de un aborto. Es lo que se puede deducir de los datos proporcionados por A. de Palencia, quien afirmaba lo siguiente:

[...] Díjose que había muerto envenenada por su hermano el rey de Portugal, por cuanto, pesarosa de su adulterio, tan funesto a los reinos de España, había querido hacer pública manifestación de su arrepentimiento. Otros afirmaron que la causa de su muerte había sido un aborto $[\ldots]^{234}$.

J. Zurita, siguiendo a Palencia, señalaba:

“[...] hubo fama que murió de ponzoña que le mandó dar el rey de Portugal, su hermano, y que dijeron algunos que murió de parto"235.

Por su parte, el autor de la Crónica incompleta de los Reyes Católicos, sin descartar la teoría del envenenamiento, apuntaba también la posibilidad de que la reina hubiese muerto de "esquinançia", es decir, de anginas. Decía así:

Sin la desafiar larga dolençia, en el término de tres días la reyna doña Juana, madre de doña Juana, por quien los fuegos de Castilla arden, fue muerta de ascondida enfermedad, muchos creyendo que, para dar fin a las culpas de su fama por la pérdida que de aquello a la hija vernía, le dieron yerbas. Otros afirmauan que de esquinançia muriese $[\ldots]^{236}$.

Por último, hemos creído conveniente incluir también, dentro de este apartado referido a los envenenamientos, el caso de Martín el Humano, cuya muerte, aunque al parecer no fue intencionada, se produjo, a juzgar por los datos que poseemos, por ingerir, posiblemente de forma masiva, medicinas para corregir su impotencia sexual. Al menos, es lo que se puede deducir de la información proporcionada por $\mathrm{J}$. Zurita, quien, refiriéndose al año 1410, señala:

[...] adoleció a 28 del mes de mayo de un tan repentino accidente que le tuvieron luego por mortal y apenas vivió dos días. Y falleció el último de mayo. Hubo, como suele acontecer, diversos juicios de la ocasión de su dolencia y túvose por lo más cier-

${ }^{232}$ Según E. Flórez, falleció en junio de 1475 (FlóRez de Setién, E.: Ob. cit., tomo 2, p. 319).

${ }^{233}$ Al parecer, nació en 1439 (Ibidem, p. 320).

${ }^{234}$ Palencia, A. de,: Crónica de Enrique IV, vol. 258, ed. cit., p. 245.

${ }^{235}$ ZuRita, J.: Anales de la Corona de Aragón, tomo 8, ed. cit., p. 249.

${ }^{236}$ Crónica incompleta de los Reyes Católicos (1469-1476). Según un manuscrito anónimo de la época, ed. cit., p. 196. 
to que adoleció de diversas medicinas y manjares muy exquisitos que le dieron para incitar su inhabilidad e impotencia $[\ldots]^{237}$.

A. García de Santa María, por su parte, afirma que el rey falleció “de su dolençia natural"'238. Tenía 54 años ${ }^{239}$.

Al referirnos a las muertes que se produjeron de forma intencionada, no podían faltar las ejecuciones. Salvo en el caso del asesinato de Pedro I de manos de Enrique II, las tres ejecuciones de las que tenemos noticia se llevaron a cabo por mandato del propio Pedro el Cruel o de su madre, la reina María. Así, por ejemplo, en 1351, cuando rondaba los 40 años ${ }^{240}$, murió ejecutada en el alcázar de Talavera doña Leonor de Guzmán. Así relata su muerte P. López de Ayala:

[...] envió la reyna doña María un su escribano que decían Alfonso Ferrández de Olmedo e por su mandado mató a la dicha doña Leonor en el alcázar de Talavera $[\ldots]^{241}$.

Unos años más tarde, en 1359, el monarca mandó asesinar a su tía Leonor, esposa de Alfonso IV el Benigno ${ }^{242}$. En la Crónica catalana de Pedro IV se describe la crueldad con la que fue asesinada la reina, que murió estrangulada con una toalla. En un pasaje de la crónica, el rey relataba así la muerte de su madrastra:

[...] Tramés en lo castell hon ella habitava .j. porter qui, com fon ab ella en la cambra, li dix: El rey, mi senyor, vos manda matar". E, tantost, ab .j. tovallola, ab que li estrengué lo coll $[\ldots]^{243}$.

\section{La reina tenía 52 años ${ }^{244}$.}

${ }^{237}$ Zurita, J.: Anales de la Corona de Aragón, tomo 4, ed. cit., p. 930. Al parecer, el monarca pudo fallecer a consecuencia de una sobredosis de cantaridina, utilizada como afrodisíaco (GARGANTILLA, P.: Enfermedades de los reyes de España. Los Austrias. De la locura de Juana a la impotencia de Carlos II el Hechizado, Madrid, 2005, p. 77).

${ }^{238}$ García de Santa María, A.: Crónica de Juan II de Castilla, ed. cit., p. 317. En la Crónica de Juan II sólo se hace alusión a la muerte del rey aragonés, aunque no se aporta ningún dato referido a las circunstancias de la misma (Crónica de Juan II, vol. 68, ed. cit., p. 327). R. Tasis señala que el monarca se sintió enfermo de repente el 29 de mayo. El día 30 su estado de salud empeoró hasta el punto de que se vió obligado a utilizar una silla de brazos, pues, al parecer, su exceso de peso le impedía respirar estando tumbado (TASIS I MARCA, R.: Ob. cit., p. 239).

${ }^{239}$ Había nacido en 1356 (Ibidem, p. 143). En la Crónica catalana de Pedr o IV no hay ninguna referencia al nacimiento de Martín el Humano.

${ }^{240}$ Dice el padre Flórez que doña Leonor de Guzmán era pocos días mayor que el rey Alfonso (Flórez de Setién, E.: Ob. cit., tomo 2, p. 146). Por tanto, debió de nacer en 1311.

${ }^{241}$ López de Ayala, P.: Crónica de Pedro I, vol. 66, ed. cit., p. 412.

${ }^{242}$ Según P. López de Ayala y J. Zurita, la muerte tuvo lugar en 1359 (López De Ayala, P.: Crónica de Pedro I, vol. 66, ed. cit., p. 493; ZuRITA, J.: Anales de la Corona de Aragón, tomo 4, ed. cit., p. 371). Sin embargo, E. Flórez afirma que la reina murió en el año 1369 (Flórez de Setién, E.: Ob. cit., tomo 2, p. 110).

243 Chronique catalane de Pierre IV d'Aragon III de Catalogne, ed. cit., p. 325.

${ }^{244}$ Nació en 1307 (Flórez de SetiÉN, E.: Ob. cit., tomo 2, p. 109). 
En 1361 también falleció por orden del monarca, a los 26 años ${ }^{245}$, su esposa Blanca de Borbón. Su muerte tuvo lugar en Medina Sidonia, donde la reina estaba presa. Según el relato de P. López de Ayala, el rey envió a Medina Sidonia a un individuo llamado Alfonso Martínez, que era físico y contador mayor del monarca, para que envenenase a doña Blanca. Pero, al parecer, Iñigo Ortiz, que se encargaba de custodiar a esta última, no quiso participar en el asesinato. Por todo ello, la reina fue entregada a un ballestero llamado Juan Pérez de Rebolledo, quien se encargó de matarla ${ }^{246}$. Seis años después, en el mes de marzo de 1369 , fue el propio Pedro el Cruel quien, a los 35 años ${ }^{247}$, murió en combate personal, como es sabido, de manos de Enrique de Trastámara. Así relata la muerte del rey el cronista P. López de Ayala:

[...] firióle con una daga por la cara e dicen que amos a dos, el rey don Pedro e el rey don Enrique, cayeron en tierra e el rey don Enrique le firió, estando en tierra, de otras feridas $[\ldots]^{248}$.

J. Zurita, por su parte, siguiendo a algunos autores cuyo nombre no especifica, relata así la muerte del rey:

[...] el vizconde de Rocabertí dio un golpe de daga al rey don Pedro y le trastornó de la otra parte y entonces el rey don Enrique se puso sobre él y le mató y cortó la cabeza con sus manos. Y echóronla en la calle y el cuerpo se puso en el castillo entre dos tablas sobre las almenas $[\ldots]^{249}$.

A modo de conclusión, podríamos decir que las fuentes historiográficas sólo en contadas ocasiones permiten identificar con cierta seguridad las enfermedades que llevaron a la tumba a los monarcas de la época, puesto que, con frecuencia, los testimonios que nos ofrecen aluden a dolencias difíciles de precisar. Otras veces, tal y como ha sido habitual hasta tiempos relativamente recientes $-\mathrm{y}$ ello se puede comprobar en los libros de defunciones del registro civil-, los datos que han llegado a nosotros se refieren únicamente a los síntomas, debido al relativo desconocimiento que se tenía entonces sobre las patologías, hasta el punto de no permitir un diagnóstico bien fundamentado y seguro. Por otra parte, y sin olvidar lo anterior, hay que tener en cuenta que quienes nos transmiten la información no eran médicos. Es evidente que estos últimos, incluso con las limitaciones propias de una época en la cual el desarrollo de la medicina era todavía modesto, tenían, sin duda, una información a menudo insuficiente, pero siempre mucho más correcta y atinada.

${ }^{245}$ Dice el padre Flórez que tenía 18 años en 1353 cuando se efectuó su boda con Pedro I y, por tanto, había nacido en 1335 (Ibidem, p. 157).

${ }^{246}$ López de Ayala, P.: Crónica de Pedro I, vol. 66, ed. cit., p. 512. J. Zurita señala: “[...] este año murieron la reina doña Blanca, la cual mandó matar el rey de Castilla con gran crueldad estando presa en Medinasidonia, y doña María de Padilla [...]" (Zurita, J.: Anales de la Corona de Aragón, tomo 4, ed. cit., p. 426).

${ }^{247}$ Nació el 30 de agosto de 1333 (Crónica de Alfonso XI, vol. 66, ed. cit., p. 264).

${ }^{248}$ López de Ayala, P.: Crónica de Pedro I, vol. 66, ed. cit., p. 592.

249 Zurita, J.: Anales de la Corona de Aragón, tomo 4, ed. cit., p. 591. 
En general, los cronistas suelen facilitar datos más pormenorizados en aquellos casos en los que la muerte se produjo de forma inesperada y violenta, hasta el punto de que podemos saber, con gran lujo detalles, qué tipo de accidentes segaron la vida de los miembros de la realeza, así como las circunstancias en las que perecieron en aquellos casos en los que el fallecimiento fue causa de un homicidio.

En todo caso, gracias a esos testimonios conocemos, en ocasiones, no sólo datos sobre las posibles causas de la muerte y las circunstancias que la acompañaron, sino también sobre la edad a la que se produjo. Es bien conocido que la esperanza de vida era corta, en comparación con lo que es habitual en nuestros días. Así, de un total de 43 casos analizados en los que se conoce la edad de la muerte, hemos comprobado que, en 18 ocasiones, el fallecimiento se produjo antes de los 40 años. De hecho, llegar a cumplir más de 70 años -entre los personajes contemplados en nuestro estudio sólo Juan II de Aragón y Juana la Loca superaron esa edad- debía de ser un privilegio para los hombres y mujeres de aquella época. 